\title{
Cuestiones sobre el Poblamiento y los modos de vida en el Neolítico interior de la Península Ibérica ${ }^{1}$
}

\author{
Sofía Sanz González de Lema
}

\begin{abstract}
Resumen
En estos momentos los estudios sobre el Neolítico de la Meseta están siendo numerosos y productivos, pero esta avalancha de datos nos obliga a reflexionar en torno a dos hechos: en qué medida las viejas interpretaciones sobre el Neolítico están afectando a la visión actual del interior peninsular y cómo se desenvuelve la información que manejamos en el presente. No obstante, en este artículo tan sólo tratamos la problemática del asentamiento y de la economía, quedando para otra ocasión la controversia de la neolitización, el mundo simbólico y la humanización del espacio.
\end{abstract}

Palabras clave: Neolítico, Cultura Central, Neolítico Interior, solapamiento, continuidad, epipaleolítico, asentamiento, economía.

\begin{abstract}
At this moments the Neolithic Meseta studies are being larges and productives, but this avalanche of information forces us to reflect on two actions: how do the olds interpretations about Neolithic affect the present view of the peninsular interior? And how does the current information develop? However, in this article only we treat the settlement and the economy problems, at other ocassion we are going to examine the neolithization, symbolic world and humanization controversy.
\end{abstract}

Keywords: Neolithic, Central Culture, Neolítico Interior, overlapping, continuity, epipaleolithic, settlement, economy.

Todo amante del bel canto sabe que los primeros movimientos que se escuchan en ciertas obras son el leitmotiv, éste recoge el motivo central y el eje de la Opera que se irá desarrollando a lo largo de las notas. En el caso que hoy nos compete, el Leitmotiv de este artículo responde a una pregunta: ¿por qué pensamos lo que pensamos sobre el Neolítico del Interior de la Península Ibérica?. Es cierto que tal cuestión es amplia e intentar enhebrar toda visión sobre el Neolítico meseteño en un espacio reducido como es un artículo no es fácil, sino imposible. De este modo, tan sólo trataremos hoy una única parcela del Neolítico de la Meseta, a saber: asentamientos

1 Este artículo es parte del Trabajo de Investigación Tutelado (2003-2004) dirigido por Dr. Dña. Isabel Rubio de Miguel profesora titular de la Universidad Autónoma de Madrid, y y economía; dejando la problemática de la neolitización, el mundo simbólico y el de las creencias, además de la domesticación y la humanización del entorno para otra ocasión.

\section{RECUERDO DE UN PASADO}

Es conocido que la investigación de esta última década ha ofrecido gran cantidad de información sobre el Neolítico del interior peninsular, sin embargo, a pesar de la unidad geográfica del territorio, los avances llegan de forma fragmentada y con diversa intensidad debido en su mayor parte a la política de

realizado gracias a la Beca de Tercer Ciclo concedida por el Rectorado de la misma universidad. 
cada autonomía; situación que dificulta la visión general y global del Neolítico en la Meseta. Así pues, hoy día se diferencian: el Neolítico de Castilla y León (Submeseta Norte), el Neolítico de Castilla La Mancha (Submeseta Sur) y el Neolítico de Madrid (zona Central); aunque en estos últimos años el Neolítico de Cáceres es propuesto dentro de la dinámica del Neolítico Interior (Cerrillo Cuenca y González Cordero, 2006). En resumen, la investigación actual se posiciona contra los tiempos pretéritos, en los cuales la Meseta era entendida como una masa informe y homogénea en cualidades: marginal, dependiente, de carácter retardatario, de hábitat en cueva, con cerámica incisa y 'a la almagra' pero con pobre material lítico, y escasamente poblada por comunidades ganaderas itinerantes -cuestión que a su vez explicaba la exigüidad de los datos existentes sobre el Neolítico meseteño-.

La parquedad de la información extraída de los yacimientos hizo que poco a poco se radicalizasen las posturas hasta consolidar la hipótesis del desierto meseteño que abarcaba desde el Paleolítico Superior hasta el Calcolítico. Este Neolítico meseteño tan 'uniforme' era comprendido bajo el nombre de Cultura de las Cuevas o Central, término acuñado por Pedro Bosch Gimpera en los años veinte y en uso hasta la década de los ochenta; momento en el que tomó el relevo la denominación del Neolítico Interior, como consecuencia del cúmulo de nuevos datos sobre la Meseta y, especialmente, por los descubrimientos de la Abrigo de Verdelpino (Fernández Miranda y Moure Romanillo, 1975), la Cueva de La Vaquera (Zamora, 1975) y la Cueva del Aire (Fernández-Possé y Arnáiz, 1980). Aunque, si bien es verdad que esta expresión otorgaba al Neolítico meseteño una mayor personalidad y rompía con la tesis del desierto meseteño, se mantenía dentro de las directrices generales dictadas por Bosch Gimpera.

Para comprender la tesis de la Cultura de las Cuevas hay que hacer el esfuerzo de mirar tras de sí, ya que está presente el evolucionismo darviniano (Darwin, 2000), el progreso cultural decimonónico ${ }^{2}$ y el degeneracionismo propio del difusionismo:

(1) En primer lugar, del evolucionismo tomó las nociones de selección natural, colonización y movi-

2 Es clarificador como Francisco María Tubino (historiador, arqueólogo, filósofo y sociólogo español del último cuarto del siglo XIX) en su trabajo Historia y progreso de la Prehistoria Arqueológica (1872) recomienda una amplia bibliografía donde figuran entre otros títulos: Descent of man de C.Darwin, 1871 (Darwin, 2002), Les habitants primitifs de la Scandinavie esaie d'ethographie comaparée. Primière Partie: l'age de la pierre de Sven Nilsson (Nilsson, miento migratorio como medios de supervivencia ante la presión geográfica y demográfica. No obstante, recordando el discurso evolucionista tomado por los prehistoriadores españoles, este evolucionismo era más cercano al lamarckiano, en el cual la 'voluntad' es fundamental en el devenir y desarrollo de las especies, que al evolucionismo de Darwin donde el azar es principio de cambio.

(2) En segundo lugar, del progreso cultural tomó la idea finalística y unilineal de humanidad. Es decir, el fin último era la civilización, por lo que la superación de los diferentes estadios: salvajismo y barbarie, tienen como objetivo final llegar a la civilización.

Sven Nilsson (1868) menciona que toda nación debe pasar por cuatro etapas antes de lograr 'su más alto desarrollo social': salvaje, pastor, agricultor y civilización. La fase salvaje se identificaba con los hombres cavernícolas e itinerantes del Paleolítico que se dedicaban a la caza y recolección, a la talla de piedra y que vivían en cueva. Por otro lado, la ganadería haría su aparición durante el tránsito a la barbarie y que, a diferencia de la agricultura, esta actividad se relacionaba con el nomadismo. La barbarie se vinculaba con el comienzo de la agricultura, la sedentarización del hombre, las primeras aldeas, los primeros utensilios de cerámica y piedra pulimentada. Por último, la civilización comienza con las culturas residentes en urbes que tienen escritura, moneda y división del trabajo.

Así pues, se relacionaban los diferentes estadios de progreso con el modelo de economía, el grado de sedentarización, el carácter de hábitat -ya sea en cueva, aldea o ciudad- y el tipo de artefacto. Ahora bien, además, en estos primeros tiempos de la "Ciencia del Hombre" se acepta la posibilidad de estancamientos en el desenvolver de las culturas, generando culturas con diferente nivel de desarrollo y creando supervivencias de elementos de periodos anteriores (Tylor, 1977).

(3) En último lugar, se encuentra el concepto de degeneración que se desprende del difusionismo y la colonización. Resumiéndose en que las sociedades receptoras de nuevas influencias tendrían siempre un grado menor de desarrollo que las comunidades emisoras de cultura.

1868), de John Lubbock cita The Prehistoric Man que con toda certeza se refiere a The Prehistoric Times publicado en 1865 (Lubbock, 1876) y The Origin of Civilization and the Social Condition Primitive Condition of Man: Mental and Social Condition of Savages en 1870 (Lubbock, 1987), obras que influyeron a la hora de abordar la prehistoria de principios del siglo XX en España. 
Cuando abordamos la Prehistoria de la Península Ibérica de finales del siglo XIX y principios del siglo XX, observamos dos hechos: (1) la evidente profusión y equívoco de terminología -eneolítico, neolítico final, neo-eneolítico...- y (2) la confusión entre los límites de la etapa neolítica y metalúrgica (Rubio de Miguel, 1995). Por lo que no es extraño escuchar al propio Bosch Gimpera indicar en $E l$ poblamiento antiguo y la formación de los pueblos de España : "los grupos de cerámica cardial parecen contemporáneos de las primeras etapas del vaso campaniforme" (Bosch Gimpera, 1974: 91) para señalar más adelante que "el vaso campaniforme representa el apogeo de la cultura eneolítica y un periodo muy largo de relaciones comerciales y de desarrollo de la metalurgia" (Bosch Gimpera, 1974: 93).

También, queremos apuntar un último detalle respecto a la lectura del Neolítico de aquellos días, según Hugo Obermaier (1932) el Neolítico alcanza su apogeo en su fase final. Esta tesis propone que en el Calcolítico se desarrollaron los avances que durante el Neolítico se habían logrado, quedando la etapa neolítica relegada a un plano secundario y transitorio en la formación de los legendarios pueblos prerromanos.

\subsection{La Cultura Central}

Basándose en la unificación de etnia-culturaperíodo histórico del modelo de los Círculos de Culturas de la escuela Histórico-Cultural de Viena -a principios del siglo XX-, Bosch Gimpera identificó cuatro círculos culturales en la Península Ibérica, estos eran: Cultura de Almería, Cultura Pirenaica, Cultura Megalítica portuguesa y Cultura de las Cuevas, que a su vez se subdividía en dos regiones, la meridional (Andalucía y Extremadura) y septentrional (región central) llamada Cultura Central.

La Cultura Central fue el primer intento de sistematización del interior peninsular, este primer acercamiento describía la Meseta como retardataria, marginal y de influencia meridional. Se consideraba que la Cultura Central era consecuencia de la migración de grupos capsienses provenientes de norte de África, que tenían su paralelo en la Cultura de las Cavernas norteafricanas o Cultura del Sahara, ya que ambas compartían el hábitat en cueva, la cerámica incisa y una lítica pobre. No obstante, la región central no se descubría tan sencilla en su formación puesto que amalgamaba diversos pueblos: paleolíticos y mesolíticos capsienses, junto a restos de grupos del este, del centro y del sur

3 Este artículo fue publicado en 1945 y posteriormente recopilado en la obra Paletnología (1974), donde se recogen los peninsular. Además, a tenor de los yacimientos descubiertos en la Meseta, la densidad demográfica sería baja y desigual.

Por otra parte, la expansión de los grupos agricultores propició el movimiento migratorio mesolítico hacia el interior a través del Sistema Central. Durante este éxodo los pueblos cazadores fueron convirtiéndose paulatinamente en pastores -habitando las cuevas y llevando una vida nómada- hasta que avanzado el Neolítico adoptan la agricultura y "colonizan las llanuras del centro de España y el valle del Guadalquivir" (Bosch Gimpera, 1974: 90).

Concluyendo, la naturaleza pastoril de los pueblos meseteños les obligaba a llevar una vida itinerante y nómada -aspecto que explicaba la escasez de asentamientos-, y a identificarse con el hábitat en cueva, la lítica pobre y la cerámica incisa. Además, contando con el paralelo de la Cultura del Sahara, la expansión de los pueblos ganaderos a través de las montañas se relacionaba con la localización del Arte Esquemático. Esta formulación supuso una barrera casi infranqueable a las siguientes hipótesis de trabajo del interior peninsular, ya que influyó a que los posteriores frutos de la investigación se amoldasen a un determinado marco teórico preestablecido.

Los deficitarios hallazgos en cueva y el olvido de los fondos de cabaña descubiertos por José Pérez de Barradas (1926) y Hugo Obermaier (1917), llevaron paulatinamente a la teoría del desierto meseteño y quedó el interior representado únicamente por cinco yacimientos: Criptana, El Conejar, Solana de la Angostura, Cabecera de Encinas y Atapuerca (San Valero, 1954). Asimismo, dentro de la lógica degeneracionista de la difusión se defendía la marginalidad de la Meseta con respecto a las novedades dadas en el resto de la península y, como corresponde, era posible la coetaneidad entre los yacimientos costeros del Bronce I, el Neolítico II de las montañas litorales, el Neolítico I de los valles del Sistema Central y el Mesolítico en las zonas más anfractuosas (San Valero, 1954). Finalmente, José Maluquer de Motes $(1958,1968)$, quien trabajó con interés en la Meseta, continuó la estela de las tesis clásica.

\subsection{El Neolítico Interior. El Cambio.}

En la década de los ochenta llegaron aires de renovación que permitieron una política de autonomías y un relevo generacional en la investigación. Pero con el cambio no llegó el fin de la confrontación entre hábitat en cueva versus hábitat al aire libre, o entre ganadería versus agricultura; ya Isabel Rubio de Miguel intuía que "ambos tipos de hábitat

escritos completos de Bosch Gimpera, y que nosotros hemos consultado. 
se encuentran desde los inicios del neolítico (y aún antes), en perfecta sincronía en diversas áreas peninsulares, incluso en la problemática región meseteña" (Rubio de Miguel, 1984-85:155). A los descubrimientos anteriormente citados de Verdelpino, La Vaquera y El Aire, se suman las revisiones de 'fondos de cabaña' que hiciese $\mathbf{M}^{\mathrm{a}}$.I. Martínez Navarrete y los nuevos asentamientos en superficie descubiertos: Km. 3,5 de la Carr. de la Vega, Madrid (Méndez y Gálvez, 1984; Mercader Florín, Cortés Busto y García de Benito, 1989 b), el Arenero de Arganda, Madrid (Mercader Florín, Cortés Busto y García de Benito, 1989 a), Vega de los Morales, Ciudad Real (Vallespín et alii; 1985) y sobre todo el paradigmático yacimiento en alto del Altotero, Burgos (Arnáiz Alonso y Esparza Arroyo, 1985). La interpretación de este conjunto de yacimientos vino a confirmar las tesis clásicas en la que se reconocía: un primer período ganadero en cueva relacionado con una primera colonización, y un segundo momento agrícola con la bajada al llano que motivó la transformación de la cueva como vivienda en un recinto funerario.

Además, como señalaron Víctor Antona del Val (1986) y Luciano Municio (1988), la búsqueda selectiva en cuevas y en altos de cerros estaba dando una visión parcial del Neolítico meseteño. Sendos autores impulsaron el estudio del Neolítico en la Meseta, Municio por su parte realizó el primer 'Estado de la Cuestión' de la Meseta Central donde se mantenían los principios clásicos: asentamientos en cueva y en alto, la distancia temporal entre ambos, y la relación entre la ausencia de asentamientos significativos con la vida itinerante de carácter estacional vinculada a una economía de amplio espectro con mayor peso en la ganadería.

Finalmente, bajo el prisma evolucionista unilineal de los materiales se pensó que la presencia significativa de cerámica lisa apoyaba la modernidad del hábitat de superficie, ya que durante el período Calcolítico abundaban las cerámicas sin decoración. No obstante, las pastas clasificadas como lisas podrían ser fragmentos libres de ornamento de un recipiente decorado, de hecho actualmente se está comprobando que tanto la cerámica como la estructura habitacional no variaron significativamente durante más de 1500 años, v.g.: los asentamientos al aire libre de La Lámpara y La Revilla, Soria (Kunst y Rojo Guerra, 1999). El problema de aquellos días era, una vez más, la ausencia de estudios químicos y petrológicos de las pastas cerámicas de la Meseta y la continuidad en la datación de los yacimientos mediante la clasificación tipológica de un único tipo material, ya fuese lítico o cerámico.

\subsection{Hacia el Futuro.}

Con la inauguración de los noventa comienzan la lluvia incesante de nuevos hallazgos que revelaron un panorama meseteño muy diferente al defendido hasta aquella fecha. Además se unió el interés de los prehistoriadores por obtener dataciones absolutas de los nuevos yacimientos. El resultado se puede resumir en cinco puntos:

1) Los hallazgos de asentamientos al aire libre se multiplicaron, doblando en número al hábitat en cueva.

2) Los asentamientos en alto de cerros comienzan a ser cuestionados como neolíticos, ya que responden tanto a prospecciones superficiales como a excavaciones no metodológicas, y los materiales recuperados son más cercanos a fechas metalúrgicas.

3) Se identificó un nuevo patrón de asentamiento: a media ladera, orientado al sur, cercano a fuentes y afluentes de grandes ríos, con control visual del territorio y de los pasos tradicionales, con rápido y fácil acceso a los recursos agrícolas, pecuarios y caza -es decir, a campos de labor, dehesas y bosques, respectivamente-, y siempre aprovechando las ventajas orográficas y climáticas de la región (Iglesias Martínez, Rojo Guerra y Álvarez Periañez, 1995). Estos asentamientos recuerdan a los 'fondos de cabaña' madrileños de carácter efímero y estacional, que posiblemente estuvieron relacionados con una economía de pluriactividad (Díaz-del-Río Español, 1998) o con un modelo habitacional estacional recurrente (Jiménez Guijarro, 1998), concepto cercano al ejemplo de asentamiento "aldeano" o village farming economies de J. Juan Manuel Vicent García.

4) También se documentan asentamientos bajo túmulo que comparte las características de los hábitats de superficie a media ladera. Este patrón responde al abandono del recinto doméstico y a la siguiente construcción del monumento funerario. El hábitat bajo túmulo ha sido localizado tanto en la Submeseta Norte como en la Submeseta Sur (Fig. 1), aunque habría que hacer una diferenciación entre aquellos que pudieron ser anteriores, coetáneos y sincrónicos a los monumentos funerarios a los que acompañan. Para Rojo Guerra, Kunst y Palomino Lázaro (2002) los únicos yacimientos con un claro horizonte premegalítico en la Submeseta Norte son La Velilla de Osorno, Palencia (Magdaleno Zapatero, 1991, Delibes de Castro y Zapatero Magdaleno, 1995), el Teso del Oro de San Martín de Valderaduey, Zamora (Palomino Lázaro y Rojo Guerra, 1997) y el complejo de La Lámpara y La Peña de la Abuela, Soria (Rojo Guerra y Kunst, 1999). Este fenómeno, como ya hemos adelantado, igualmente se documenta en el sur de la Meseta con los dólmenes de Azután y Castillejos, Toledo (Bueno Ramírez et alii; 2002).

Tal vez, lo más extraordinario de estos descubri- 
mientos es que se sitúan en zonas donde tradicionalmente existían sepulturas monumentales (megalitos, túmulos...), pero donde se ausentaban los asentamientos. Para dar explicación a este hecho se proponía que los poblados de los constructores megalíticos serían poco significativos debido al carácter ganadero e itinerante de estas comunidades (Maluquer de Motes, 1958). Sin embargo, hoy día las comunidades constructoras muestran mayor complejidad en sus actividades económicas y dejan de ser clasificadas como únicamente ganaderas.

Finalmente, la lectura de estos asentamientos puede ser variada: continuidad megalítica de los asentamientos neolíticos traduciendo que "las estructuras previas al túmulo y éste muy probablemente fueron manifestaciones del mismo grupo social, y que las importantes diferencias apreciadas en cuanto a cultura material en uno y otro ambiente debieron responder a un fenómeno de especialización funcional" (cursiva del autor. Zapatero Magdaleno, 1991: 60). También pueden responder a ritos fundacionales previos a la erección del monumento, de tal suerte participarían de la misma cronología (Zapatero Magdaleno, 1991, 1993). Incluso pueden atender a la correlación entre yacimiento funerario y restos episódicos de ocupación bajo éstos o en su periferia "como resultados de episodios de agregación social que implica el asentamiento periódico en torno a los túmulos, la construcción de monumentos en unos casos y la realización de prácticas rituales y acontecimientos festivos en otros y, simultáneamente, el uso y explotación del entorno" (Criado Boado et alii, 2000: 297).

5) Respecto a la ocupación en cueva, ésta ha sufrido un giro importante en su interpretación durante los últimos años. Los trabajos de Badal García (2002) en el Levante peninsular sobre la utilización de las oquedades como establos, también han influido en otras áreas como en la Alta Extremadura (González Cordero, 1999) e incluso en Albacete, donde el abrigo de Molino del Vadico en Yeste aporta datos arqueozoológicos y paleobotánicos que señalan su uso como aprisco (Rodríguez González, 2006). Actualmente, habría que afrontar que las oquedades deberían ser clasificadas partiendo de la morfología: covachas, abrigos y cuevas; además de la funcionalidad que desempeñaron: vivienda, refugio, santuario y cementerio. La mayoría de las oquedades no pueden albergar a un grupo numeroso y el aumento de descubrimientos de asentamientos al aire libre dejan en clara minoría a las

4 Nos vemos en la necesidad de apuntar el hecho de que en ambos casos el estudio tipológico de un único material, el estaciones cubiertas. La suma de estos hechos nos obliga a pensar en otras posibilidades de uso e interés, bien sea refugio temporal, establo o almacén, bien sea santuario, enterramiento, etc...-.

En cuanto a la cronología absoluta todavía son escasos los yacimientos datados, pero se puede hacer cierta valoración, como la contemporaneidad de hábitat en cueva y al aire libre, o la práctica de la agricultura en un momento temprano, o bien la simultaneidad del cultivo y la ganadería por una misma comunidad (Fig. 2).

Por último, mencionar la existencia de dos características que se encuentran, tanto en conjunto como por separado, en la distribución de los asentamientos al aire libre y en cueva, estas son: solapamiento territorial y continuidad.

Se está documentando el solapamiento territorial asimismo entre estaciones epipaleolíticas y neolíticas, como entre los propios asentamientos neolíticos. La prospección del valle de Atapuerca, Burgos (Navarro Ruiz, 2002) y del valle del Sorbe, Guadalajara (Pastor Muñoz, 2000) está demostrando que existe el solapamiento entre ambos tipos de estaciones ${ }^{4}$. Por el contrario, en el valle de Ambrona, Soria (Kunst y Rojo Guerra, 1999), en el cañón del Duratón, Segovia -La Nogaleda y El Espino (Lucas Pellicer et alii, 2001)- o en la región madrileña la Cueva del Aire y la covacha de La Higuera (Barrio Martín y Rubio de Miguel, 2002) constatan el solapamiento tan sólo entre yacimientos neolíticos. Estos datos pueden responder a una coetaneidad o a una continuidad en el tiempo, ya sea de las diversas comunidades descritas ya sea de un mismo grupo humano, que condicionado por un medio de vida basado en la movilidad se ve obligado a la ocupación estacional del territorio.

Respecto a la continuidad de estratos epipaleolíticos y neolíticos en ciertos yacimientos como Verdelpino (Fernández Miranda y Moure Romanillo, 1975) y La Higuera (Jiménez Guijarro, 1998), son la evidencia más firme de la directa relación entre poblamiento el Epipaleolítico y el Neolítico. El descubrimiento cada vez más común de yacimientos epipaleolíticos en el interior peninsular -v.g.: El Parral, Segovia (Jiménez Guijarro, 2001 a), valle del Sorbe y Atapuerca- contrasta con el vacío descrito por Juan-Cabanilles (2002) quien se esfuerza en interpretar los datos a través del marco teórico difusionista y el modelo dual; pese a que, a la luz de los nuevos hallazgos, parte de la investigación actual aboga por la continuidad entre

lítico, ha guiado la determinación crono-cultural de los yacimientos. 
el substrato epipaleolítico y el poblamiento neolítico (Jiménez Guijarro, 1998, 1999, 2001 a; Hernando, 1999).

Finalmente, el solapamiento, la continuidad y lo efímero de los poblados podría estar desvelando un modo de vida basado en la movilidad y la pluriactividad de carácter estacional, en la que la agricultura de roza, la ganadería transterminante, la caza y recolección, y el intercambio de bienes tienen cabida.

\section{LA COSTUMBRE DE LA CASA.}

Cuando abordamos la espinosa cuestión de los modos de vida corremos el riesgo de dejarnos llevar por el torrente de descripciones y anotaciones fugaces, tal vez un buen comenzar sería preguntarse por lo más elemental del ser humano: su naturaleza. Ernst Cassirer ${ }^{5}$ (2000), propone la doble naturaleza del hombre: la naturaleza animal, base biológica y orgánica, y la naturaleza simbólica mediante la cual el ser humano percibe la realidad de forma más amplia que el resto de los seres vivos, ya que supone sobrepasar los límites de la vida orgánica para dar paso a un mundo simbólico donde: mito y religión, lenguaje y arte, historia y ciencia, son parte de este universo. En pocas palabras, el hombre se definiría como animal symbolicum.

He aquí el problema que se desprende cuando deseamos comprender la economía de tiempos pretéritos ¿a qué naturaleza damos más peso? La naturaleza animal reclama el agua y el alimento necesario para la subsistencia, esta situación hizo pensar que el hombre prehistórico se asemejaba a un "estómago bípedo", como indicó Denell (1999); tan sólo la lucha por los recursos alimenticios era el parámetro en el cual se podía entender los actos humanos, dejando de lado las motivaciones ideológicas y

5 Ernst Cassirer (1874-1945) filósofo neokantiano sometió las ciencias a un análisis filosófico y estudió las formas fundamentales de la compresión del mundo, siendo estas formas fundamentales 'formaciones simbólicas'.

6 Una de las últimas propuestas sobre la identidad en la historiografía española es el trabajo de Almudena Hernando (2002), en donde denomina como 'identidad', "a la capacidad de formar una imagen de nosotros mismos y del mundo que nos provea de suficiente sensación de seguridad y orientación como para operar satisfactoriamente en una realidad definida por la interacción, a la difícil negociación de alianzas, identidades y diferenciaciones a través de las cuales llegar a descubrir que somos capaces de sobrevivir equilibradamente en un mundo donde el equilibrio parece difícil de obtener. Creo firmemente en el carácter negociador de la identidad, en su sustancia cultural y no biológica. Creo que la identidad es una construcción que la sociedad genera en sus parámetros básicos porque constituyen la contraparte cognitiva de su modo material de relación con la realidad. Por todo ello, creo que no hay identidades mejores ni peores, sociales. Denell puso de relieve la necesidad de contemplar tanto el medio físico y medioambiental como el medio social en el que se desarrollaron los grupos humanos, para poder interpretar aquello que queda inscrito en los yacimientos. En pocas palabras para comprender la economía en un sentido amplio $\mathrm{y}$, tal vez, más arcaico del término (oikídiov: casa, vóuоc: costumbre, norma, ley); es decir para poder acercarnos a la costumbre de la casa, es necesario comprender la naturaleza simbólica del hombre. Tampoco Gordon Childe era ajeno a la importancia del medio social e ideológico, consideraba al hombre un ser natural unido a la técnica -respuesta de adaptación al medio-, diferenciando además entre el equipo material (herramientas) y el equipo espiritual (lenguaje, ideas, creencias, religión e ideología). La cultura, por otro lado, sería la convención por parte de la comunidad tanto de la abstracción del equipo espiritual como de la función y ciencia del equipo material.

Según Gordon Childe $(1997,2002)$ mediante la cultura material se puede reconstruir parte de los medios de producción y las relaciones de producción, a partir de la cual se accedería a la estructura económica de la sociedad y mediante ésta se llegaría a conocer la ideología. La propuesta de Gordon Childe es tentadora pero caeríamos en el materialismo histórico, auque sí anotamos la propuesta del arqueólogo australiano en la que asume la influencia mutua entre economía e ideología, "por lo tanto, podemos decir que las relaciones de producción deben ser lubricadas con el sentimiento" (Childe, 1971: 124). Posiblemente estemos ante uno de los puntos más dolorosos de la historiografía actual: el planteamiento de la identidad en las comunidades ${ }^{6}$. Así pues parece resumirse que la propuesta sobre la identidad es dependiente en gran medida de la eco-

más inteligentes o menos, más <<progresivas $>>$ que otras. Todo modo de identidad es un modelo de supervivencia, una forma en extremo lúcida de encarar las condiciones materiales de las que se parte" (Hernando, 2002: 205).

Esta formulación de la "identidad" para su correspondiente puesta en práctica en arqueología tal vez deba ser considerada con sumo cuidado, especialmente cuando nos confiesa que cree "firmemente en el carácter negociador de la identidad, en su sustancia cultural y no biológica" (cursiva nuestra). Autores como Ernst Cassirer (1874-1945) han insistido que si bien "en el mundo humano encontramos una característica nueva que parece constituir la marca distintiva de la vida del hombre [es decir], el sistema <<simbólico>>" (Cassirer, 2000: 47) "es obvio que este mundo [humano] no constituye una excepción de esas leyes biológicas que gobiernan la vida de todos los demás organismos" (Cassirer, 2000: 46). En resumidas cuentas: no podríamos olvidarnos, según esta idea, de la parte biológica de la naturaleza humana, naturaleza que no sería -por lo tanto- estrictamente cultural (si bien debería serlo principalmente). 
nomía en tanto que los grupos humanos se identifican según las actividades a las que se dedican.

Haciendo memoria de lo descrito hasta ahora, se resumen en que las primeras comunidades neolíticas se diferenciaban de las etapas anteriores por la adopción de la economía de producción. Incluso, la investigación tradicional relacionaba la presencia de ciertos tipos de tekné con el Neolítico, de esta manera la presencia de cerámica y piedra pulimentada era el testigo presencial de la primera agricultura y de la sedentarización de las gentes. En el caso del interior peninsular, además, se identificaba la agricultura con los poblados al aire libre y con la vida sedentaria, y la ganadería con las cuevas y nomadismo. Según la corriente clásica, la adopción del modelo económico de producción fue implacable con los modos de vida anteriores; no obstante, esta visión tradicional aplicada a la Meseta se vio enturbiada con el registro arqueológico de Verdelpino.

\subsection{Medio Físico y Climático.}

Respecto al medio físico en el que se desarrollaron estas primeras sociedades productoras, tenemos poca información. Los análisis polínicos y antracológicos son muy escasos pero al menos en su mayoría delatan que "la Meseta sería una zona estépica, sin árboles salvo excepciones a nivel local, favorecida por el suelo y el clima" (Barrio Martín y Rubio de Miguel, 2002: 28). Durante estos últimos 8000 años ha habido un clima benigno cuya consecuencia ha sido una cubierta vegetal sin cambios bruscos, siendo a partir del Sub-boreal cuando se detecta la acción del hombre. Sin embargo para que la actividad antrópica repercuta en el paisaje debe de haber una práctica continuada de ganadería o agricultura durante tan sólo 400 o 500 años, y en el caso de que el lugar sea abandonado con anterioridad los cambios apenas son perceptibles (Badal García, 2002: 143). Fig. 3.

\subsection{EL POBLADO Y SUS ALREDEDORES.}

Anteriormente hemos visto los diferentes tipos de asentamientos al aire libre (en alto, media ladera, en llano o bajo túmulo) y en covachas, abrigos o cuevas en zonas de serranía. A pesar de la diversidad, todos tienen en común: su localización estratégica en la obtención de recursos agrícolas (campos de labor), ganaderos (dehesas) y cinegéticos-recolección (bosques), también disfrutan del fácil y rápido acceso tanto a pasos naturales como al agua, y, por último, es visible el solapamiento territorial e inestabilidad de los asentamientos.

La investigación realizada por Rubio de Miguel sobre la economía neolítica en la Península Ibérica propone que la agricultura no es sinónima a pueblos sedentarios (Rubio de Miguel, 1989); pues la agricultura de rozas, sistema agrícola posiblemente practicado por los agricultores iniciales, implica una gran movilidad. Denell (1999) comparó el desplazamiento entre animales gregarios, comunidades cazadoras-recolectoras, agricultoras de rozas y pastoras, el resultado fue el alto grado de dinamismo de los pueblos agrícolas cuya táctica de supervivencia, a semejanza de los cazadores recolectores y pastores, seguía siendo la movilidad.

Tal vez, la problemática del hábitat en la Meseta comience a esclarecerse en el momento en el cual nos preguntemos ante qué tipos de asentamientos estamos: estacional, semipermanente, permanente $\mathrm{u}$ ocasional. Tradicionalmente se ha relacionado la ausencia e inestabilidad de los poblados con una vida itinerante derivada de la actividad ganadera. De este modo, los estudios de prehistoria apuntan que las formas de vida 'seminómadas' estuvieron presentes en la mayor parte de las fases culturales de la Meseta, hasta la introducción del hierro, implicando con ello una ocupación periódica marcada por la actividad estacional. Es decir que nos encontraríamos frente a una población con economía de amplio espectro (Municio, 1988).

En este punto, Díaz del Río Español discrepa con la historiografía tradicional, según la cual una aldea estable durante el III y II milenio a.C parece imposible. El arqueólogo señala que la existencia de una economía agraria con infraestructura y donde tiene cabida la horticultura contradice la postura clásica (Díaz-del-Río Español, 1998).

Por otro lado, la presencia de numerosos silos en los 'fondos de cabaña' calcolíticos madrileños señalarían que hubo un período embrionario durante el Neolítico. En otras palabras, "frente a la hipótesis de un 'vacío poblacional', la existencia de abundantes yacimientos calcolíticos hace previsible suponer que la consolidación del patrón de poblamiento de la primera edad de los metales cuente con un desarrollo preliminar en momentos neolíticos" (Díaz-delRío Español, 1998: 39, Vol I), esta intuición poco a poco parece confirmarse con la suma de nuevos descubrimientos y la revisión de los 'fondos de cabaña' descubiertos durante el siglo pasado.

Los análisis polínicos y antracológicos apenas observan cambios importantes en la cubierta vegetal que reflejen una actividad agresiva con el medio o una especialización en la obtención de recursos; o lo que es lo mismo, no hay muestras que delaten la tala de árboles ni la expansión de pastos y sembrados. Aunque los pólenes recogidos del asentamiento bajo 
túmulo de Azután indican que "el grado de antropización del medio ya seria ligeramente elevado, con un amplio desarrollo de formaciones nitrófilas. Sin embargo en este período no se detecta, al menos en estas muestras, ni el cultivo, ni la presencia del olivo o el cereal en el diagrama polínico" (López Sáez y López García, 2005: 232).

De tal suerte, en la Meseta hasta el III milenio $\mathrm{BC}$ no se perciben estas actividades productoras; por lo que es presumible que aquellas comunidades neolíticas conservaran la importancia de la caza y la recolección, y se encuadraran dentro de la pluriactividad campesina ${ }^{7}$ basada en la diversidad de recursos y prácticas productivas. Este modelo favorecería la fundación de poblados estacionales y viene a apoyar la localización de los asentamientos en zonas intermedias con sencillo y pronto acceso a áreas de pasto, de labor y de bosque.

Otra propuesta a considerar es el modelo habitacional estacional recurrente defendido por Jiménez Guijarro, en el cual se contempla la posibilidad de una economía mixta o de amplio espectro inspirada en la tesis de Díaz del Río Español y en el asentamiento tipo aldeano de Vicent García. Para Jiménez Guijarro en la primera etapa de la neolitización se conservaron fórmulas tradicionales de subsistencia, aunque rápidamente la ganadería obtuvo importancia con la estabulación del ganado y el movimiento de reses. Por el contrario la agricultura sería de ciclo corto y con cultivo de leguminosas, de esta forma la economía de amplio espectro permite una explotación estacional del territorio, lo que explica el solapamiento y la inestabilidad de los asentamientos. Además, Jiménez Guijarro, comprende la existencia de hábitat en cueva y al aire libre dentro de un mismo sistema de biestacionalidad del aprovechamiento del medio. Finalmente, el prehistoriador observa que el modelo habitacional estacional recurrente ya estaba presente en el substrato epipaleolítico anterior por lo que sería "el marco idóneo para el establecimiento de una economía 'experimental' de producción” (Jiménez Guijarro, 1999: 496).

Aún existiendo diferencias entre los diversos patrones económicos presentados, todos los autores que apuestan por una economía de producción basada en la movilidad y el amplio espectro confluyen en dos puntos: (1) la movilidad permite el contacto con otras comunidades afines favoreciendo la supervivencia de la comunidad y (2) una economía fundamentada en la pluractividad propicia el reparto de las actividades entre los individuos de la tribu,

7 El término de pluractividad campesina es tomada del modelo propuesto por Díaz-del-Río Español (1998) para el III y II teniendo tal distribución de labores su origen en el seno de las sociedades mesolíticas.

Por último, es visible la propensión general de la investigación por considerar a la ganadería como actividad esencial en el interior sólo que: ¿hacia qué estrategias productivas tienden los diferentes grupos humanos que se encontraron en la Meseta Central? ¿Necesariamente tiene que ir encauzada a la ganadería? ¿La presencia de silos y grandes contenedores no inducen a pensar que se podría llevar una actividad agraria, especialmente en lugares de tradición cerealística como en los casos de Velilla Osorno, La Lámpara, La Revilla, El Teso del Oro, La Cañadilla de Peñafiel o Los Barruecos?

\subsection{MODOS DE VIDA: ENTRE RESES, TRIGO Y PUCHEROS.}

Aún con escasos estudios tafonómicos, arqueozoológicos y polínicos realizados en los yacimientos, junto con la práctica ausencia de análisis químicos de las pastas cerámicas, se ha podido intuir, más que reconstruir, los modos de vida de aquellos primeros agricultores y ganaderos. Por desgracia, el deseo natural de cualquier investigador por desenmascarar los prejuicios y 'mitos' históricos se ve gravemente comprometido cuando se desconocen este tipo de datos en los yacimientos, de aquí surge la urgente necesidad de realizar análisis de este carácter.

Dentro de los hallazgos más sobresalientes descubiertos en la Meseta, se encuentra el abrigo de Verdelpino, tanta fue la sorpresa de sus depósitos que ha obligado a estudiar la posible filtración de materiales modernos en los estratos inferiores y el resultado ha sido negativo (Rasilla Vives, Hoyos Gómez y Cañaveral Jiménez, 1997). La peculiaridad de este yacimiento se debe a tres razones: en primer lugar con la presencia de 19 fragmentos cerámicos en el nivel epigravetiense -Corte 2, nivel IV-. En segundo lugar, existe una continuidad y equidad entre los porcentajes de fauna doméstica (ovicápridos, bóvidos y suidos) y salvaje en todos los niveles neolíticos I, II y III (Rubio de Miguel, 1988). En último lugar, las fechas absolutas equiparaban el Neolítico del Interior con el resto de la Península Ibérica. Fernández Miranda (1975) denominó al nivel IV como epipaleolítico/mesolítico con cerámica, ya que la lítica tenía carácter epigravetiense y predominaba la fauna salvaje.

Respecto a la paridad entre los índices de fauna 
salvaje y doméstica estaba en clara sintonía con lo que se descubría en otras regiones europeas y, además, esta situación volvía a recordar el problemático papel del substrato epipaleolítico en la neolitización. Como indicó Rubio de Miguel, los nuevos descubrimientos "revelarían de todos modos una actividad que demuestra que estos grupos humanos no se limitaban a recibir pasivamente las ideas venidas del exterior y que el germen de las trasformaciones acaecidas posteriormente se hallaba latente en estas sociedades de cazadores-recolectores" (Rubio de Miguel, 1988: 396).

En la Vaquera desde un primer momentos también se documentó ovicápridos, seguidos de vacuno y porcino; pero el consumo de piezas de caza no perdió peso con respecto al animal doméstico (Rojo Guerra y Estremera Portela, 2000). Este dato viene a acompañar las aportaciones de Verdelpino, ya que la fauna salvaje mantiene su alto grado de presencia durante la etapa neolítica (Fig. 4). En líneas generales, la fauna salvajes recuperada más significativa son los ciervos, équidos y lagomorfos; en torno a los animales domésticos la cañada de ovicápridos es la más temprana y la más abundante, posteriormente se diversifica con bóvidos y -en menor medida- con el cerdo.

En el caso del abrigo de La Ventana (Torrelaguna, Madrid) cuya ocupación neolítica responde al ámbito funerario, la fauna doméstica no se encuentra entre los restos óseos analizados del nivel neolítico (Sánchez et al., 2005), aunque sí hay semillas que delata el cultivo de cereal (Jiménez Guijarro y Sánchez Marco, 2005).

Finalmente, entorno a la relación de los abrigos y cuevas con la ganadería, la presencia de cerramientos que indican la estabulación de ganado en oquedades del Levante -Cueva de Cendres, Cueva de Santa Maira, La Falaguera, Cova Bolumninia y en algunas ocasiones en la Cova de l'Or (Badal García, 2002)-, ha permitido que Jiménez Guijarro (1998) defienda la misma hipótesis de trabajo para Verdelpino (Cuenca), Los Enebrales, El Reno y Sedan del Batán (Guadalajara). Pero los cerramientos de estas cavidades carecen de testimonios claros que les señalen como neolíticos y, además, tampoco tienen dataciones absolutas. No obstante, aunque los ejemplos propuestos por Jiménez Guijarro no sean los más adecuados, los ejemplos levantinos aún pueden ilustrar sobre lo que pudo ocurrir en algunas covachas y cuevas de la Meseta.

En cambio, cuando nos acercamos a los asentamientos al aire libre, recibimos datos que sí concluyen la existencia de apriscos. En las cabañas infratumulares de Azután y en las chozas situadas alre- dedor del dolmen de los Castillejos se han descubierto esporas fúngicas, las cuales pueden ser consideradas como resultado de la estabulación de reses. Estos datos son corroborados por los restos de Bos y Ovis recogidos en Azután y los punzones sobre hueso de ovicáprido (Bueno et alii, 2005 a, 2005 b).

También se han encontrado restos de fauna consumida -Capra, Ovis y Sus doméstico junto a Cervus- en el hogar tipo cubeta de Velilla de Osorno (Delibes de Castro y Zapatero Magdaleno, 1995) que nos señala la práctica de la ganadería y de la caza.

Para Rubio de Miguel, a medida que avanza el Neolítico y llega el Neolítico Final "la caza parece haberse convertido en una actividad de apoyo exclusivamente y la aportación de carne a la dieta recae sobre las especies domésticas" (Rubio de Miguel, 1989: 19). También contamos con evidencias indirectas de la actividad cinegética en las puntas de flecha halladas en los yacimientos y en las escenas de caza del Arte Rupestre, donde el ciervo tiene gran importancia.

Por otra parte, según sugiere Muñoz LópezAstilleros (1998), la leche tuvo un importante papel en la dieta y en tal caso las comunidades tuvieron que contar con una cañada estable de ovicáprido y/o de bóvidos. Los estudios faunísticos de La Vaquera (Rubio de Miguel, 1988 y Estremera Portela, 2003) o de Velilla de Osorno (Delibes de Castro y Zapatero Magdaleno, 1995) revelan que el ovicáprido está presente desde los momentos más antiguos, y que posteriormente rivaliza con el ganado vacuno y porcino, pero siempre con clara superioridad.

En cuanto a las evidencias directas sobre el consumo de lácteos en la Meseta, se han constatado en momentos posteriores con los enterramientos en el domen de Azután. Según Bueno Ramírez (2005 a) los restos óseos de los difuntos contenían un alto grado de vanadio, elemento que delata una alta ingesta de lácteos. No obstante, podemos remitirnos al enterramiento del IV milenio cal.BC de $\mathrm{Ca}$ l'Oliarie (Barcelona), donde los análisis de una de las cerámicas del ajuar indican que contuvieron productos lácteos -Martín et alii (2005)-.

Finalmente, dentro de la dinámica descubierta en el Interior encontramos el asentamiento al aire libre de Los Barruecos (Cáceres). Aquí se han documentado hasta tres ocupaciones neolíticas, que sus excavadores identifican con el Neolítico Antiguo, Medio y Final, durante las cuales se practicó una economía agropastoril desde finales del VI milenio cal.BC y que fue consolidándose hasta el IV milenio. Ahora bien, cuando se han realizado los estudios de fauna éstos no han aportado casi información. En cambio, 
los datos palinológicos y sedimentarios han descubierto la presencia de dehesas junto a campos de cereal y también ha identificado restos de hongos coprófilos, propio de una actividad ganadera estabulada (Cerrillo Cuenca et alii, 2005).

A pesar de que los estudios sobre los restos de fauna no han hecho hincapié en la edad y sexo de la cañada sacrificada, estos análisis podrían indicar en qué medida la economía dependió de una actividad pastoril planificada; práctica que se ha ido defendiendo hasta el momento (Antona del Val, 1986; Municio, 1988; Zapatero Magdaleno, 1991,1993; Delibes de Castro y Zapatero Magdaleno, 1995; Jiménez Guijarro, 1998; Díaz del Río, 1998; Muñoz LópezAstilleros, 1998; Rojo Guerra y Estremera Portela, 2000; Bueno Ramírez et alii, 2002). O por el contrario, también los análisis faunísticos podrían indicar la ausencia de planificación, hallándonos entonces ante comunidades con ganadería cuyo sostén económico se repartiría en otras actividades, ya sea la agricultura, la caza, la recolección o la reciprocidad -intercambio de bienes, favores y trabajo ${ }^{8}$.

De las estructuras descubiertas en los asentamientos contamos con cabañas que podrían indicar unidades familiares de producción -La Lámpara, La Revilla, Velilla de Osorno, Teso del Oro, Peña Bardal (Ávila) ${ }^{9}$, Túmulo de los Castillejos, Túmulo de Azután y La Deseada- y con silos -La Lámpara, La Revilla, Teso del Oro ${ }^{10}$, Mesegar del Tajo

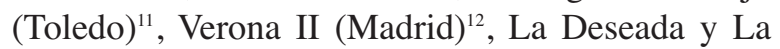
Vaquera $^{13}$.

La distribución interna de los poblados y del interior de las cabañas no manifiesta jerarquización alguna. El espacio doméstico queda constituido por un hogar central, en algunos casos de cubeta -Velilla de Osorno-, y en el único yacimiento donde se ha documentado un pavimento de madera -Teso

8 Este término es recogido entre otros por E.R. Service (1984) quien identifica tres tipos de reciprocidad: "La reciprocidad generalizada es una forma de intercambio basada en la presunción de que la devolución ocurrirá a la larga. [...] La reciprocidad compensada, por el contrario, implica un intercambio directo y explícito que es (en el sentido ideal) satisfactorio para las dos partes en términos de los bienes o de las acciones que intercambian.[... y] La reciprocidad negativa implicaría naturalmente la falta de reciprocidad o lo opuesto a la reciprocidad: el robo o la apropiación violenta de bienes" (Service, 1984: 24-25).

9 Gutiérrez Palacios (1961) identifica a la cabaña con un 'fondo de cabaña', también se documentan en el yacimiento restos de muretes o paravientos.

${ }^{10}$ Se documenta un 'hoyo' en los niveles IV y III, pero que se desconoce su funcionalidad (Palomino Lázaro y Rojo del Oro en el nivel III y unidades C y D- tampoco hay evidencias de la división en estancias del cubículo. Por otra parte, no parece que las cabañas estuvieran destinadas a una actividad concreta -salvo la de vivienda- y ninguna muestra preeminencia sobre el resto; de tal suerte que es difícil advertir la organización social a través de la ordenación espacial de los asentamientos y de las cabañas.

En relación a los silos localizados dentro de los poblados, en todos los ejemplos se localizan fuera de las cabañas y sin intención de ocultamiento (Fig. 5). Pero además se documenta tanto en La Lámpara (Rojo Guerra y Kunst, 1999) como en Valdivia Oeste $^{14}$ (Jiménez Guijarro, 2000 b) la reutilización de estas estructuras como fosa funeraria con cronología neolítica. También estaría relacionado con el espacio doméstico el enterramiento de Villamayor de Calatrava (Ciudad Real), ya que la tierra de colmatación fue extraída de un área de habitación con coloración diferente a la del resto (Rojas RodríguezMalo y Villa González, 1995).

El almacenamiento y la conservación de los productos cultivados es "la operación que define mejor una economía de producción de alimentos" (Buxó, 1997: 180), ya que indica planificación y organización de la producción, puesto que una parte del grano almacenado se conserva para la futura siembra y otra parte para el consumo. El grano puede ser preservado en silos, en grandes contenedores cerámicos, de madera y cestería, y/o en fosas en cueva -lo que quitaría cierto protagonismo a la actividad pecuaria de las oquedades-. Respecto al consumo del cereal suele ser torrefactado y tostado, generalmente esta transformación de la semilla es más común en los cereales vestido, aunque durante el Neolítico en la Península Ibérica el tueste del trigo desnudo fue común -sea por una mejor ingestión,

Guerra, 1997).

11 Mesegar del Tajo (Villa González y Rojas Rodríguez Malo, 1995) cuenta con materiales cerámicos neolíticos procedentes de tres de los veintisiete 'fondos de cabaña' excavados, el resto de los vestigios eran calcolíticos.

${ }^{12}$ La memoria de la excavación aún no ha sido publicada, no obstante Rubio de Miguel (2000) adelanta la existencia de silos en este poblado al aire libre.

${ }^{13}$ Se cuentan 10 'hoyos' en niveles los neolíticos (Estremera Portela, 1999).

14 Yacimiento madrileño excavado por Pérez de Barradas en los años veinte del siglo pasado. La revisión realizada por Jiménez Guijarro (1999 b) sobre la inhumación de Valdivia determinó que era neolítica a raíz de la errónea catalogación de una cerámica con forma de botella y con decoración incisa. 
un secado más rápido de la siembre o por higiene-. Finalmente, otra transformación del cereal para el consumo es la molienda mediante la cual se obtiene harina.

La localización de los silos en los asentamientos al aire libre nos puede estar señalando que el "almacenaje subterráneo a largo plazo ordenado sin muestras de ocultamiento puede reflejar la ausencia de pago de tributo, tensiones intergrupales o intragrupales. Por el contrario expresarían cierta autoorganización colectiva de la producción" (Díaz del Río Español, 1998: 327). Por otra parte, la presencia de silos u hoyos en cuevas nos recuerda la controvertida situación en la que actualmente se encuentra el hábitat en cueva y la funcionalidad de carácter secundario que pudo desempeñar.

Según Germán Delibes de Castro y Pedro Zapatero Magdaleno (1995) consideran que las primeras comunidades productoras de la Meseta tuvieron un poblamiento disperso y de vida itinerante; sin embargo, el hecho de que Velilla de Osorno tenga hogares, hoyos y silos es consecuencia de una "economía de almacenamiento" o "stockage". Una vez más, es visible la complejidad de los grupos neolíticos del interior, la presencia de este tipo de estructura nos previene de la cómoda denominación de aquellas primeras comunidades productoras como pastoras o ganaderas.

Otras evidencias indirectas de la actividad agrícola se encuentran tanto en los grandes recipientes globulares destinados al almacenaje de frutos secos, cereales o leguminosos; como también en los elementos de hoz, hachas, azuelas, molederas y manos de molino -que indicarían la preparación del campo de labor, la siega y la transformación de la semilla en harinas para su posterior consumo.

Además se han hallado testimonios directos de agricultura: en La Lámpara y La Revilla, Triticum monococcum -tipo bastante común en la Península Ibérica a partir del IV milenio- (Kunst y Rojo Guerra, 1999). De la zona doméstica de Azután se analizó un molino que ha ofrecido restos de cereal Triticum aestivum/durum y Triticeae-. Aún así no se conoce si son evidencias del trabajo de descascarillado del grano o por el contrario son de la molienda (Tresserras y Matamala, 2005). En los Barruecos de Malpartida (Cáceres) se cuenta con Triticum diccocum y Triticum aestivum/durum de tipo compactum, tipos relacionados con el Neolítico Antiguo / Antiguo Avanzado (Cerrillo Cuenca et alii, 2002). Respecto a La Vaquera, aquí se han hallado Triticum aestivum/durum como tipo dominante frente a los trigos vestidos y cebadas (López García et alii, 2003), situación que se repite en La Ventana (Jiménez Guijarro y Sánchez Marco, 2004).
No obstante en el desenvolver agrícola de la península hubo preferencia por la cebada frente al trigo, posiblemente debido a la rusticidad y resistencia de ésta (Rubio de Miguel, 1988). Por otro lado, también, se han recuperado muestras de leguminosas -Vicia y Lens- en la cueva de La Vaquera, pese a que la legumbre tuvo más presencia en el Bronce Final (Rubio de Miguel, 1988).

Por otro lado, la recolección de frutos en momentos neolíticos ha sido escasamente registrada y estudiada. Por fortuna, cada vez son más los estudios que atienden a esta actividad, un ejemplo son los análisis macroscópicos de los molinos recuperados del área habitacional de Azután, los resultados prueban la molienda de bellota (Tresserras y Matamala, 2005). Este dato no sorprende pues los pólenes de Azután indicaban la existencia de un entorno de dehesa (López Sáez y López García, 2005). Además, este hecho no hace mas que coincidir con otros hallazgos neolíticos peninsulares (Fig. 6) y delata la continuidad de una práctica común en el mesolítico como fue la recolección de bellotas -Font de Ros (Bordas Tissier et alii, 1996), Atxoste (Alday Ruiz, 1997) y Margineda (Guilaine et alii, 1995), entre otros-. La pregunta obligada es determinar si la recogida de bellota supone su aumento en los niveles neolíticos - el caso de Margineda- o su descenso en los casos de Font de Ros y Atxoste.

Ahora bien, sobre este último hallazgo, Primitiva Bueno et alii (2005 a) dan un nuevo giro a la interpretación y proponen a "la dehesa como un sistema de cultivo de origen neolítico" (idem 2005: 86), siendo además "una explotación más rentable en un modo de vida de carácter fuertemente mixto" (idem 2005: 88).

Finalmente, sin salir del entorno de la recolección, en Azután también se recuperó una vasija con restos de haber contenido miel o hidromiel (Tresserras y Matamala, 2005) que directamente nos recuerda las pinturas rupestres de la Araña (Bicorp).

En conclusión, parece evidente que hubo cierta continuidad en algunos aspectos de los modos de vida mesolíticos como el importante aporte de la caza y la recolección, junto con la movilidad del grupo humano; hechos que están acorde al resto de Europa.

En torno a las formas y tipos cerámicos, la cerámica cobra un sentido más amplio en el momento en el que se deja a un lado su papel como vestigio de la neolitización, para convertirse en lo que realmente es: un recipiente donde se elaboran y se contienen comidas y bebidas. La presencia de cerámica con o sin decoración ha hecho que se especule sobre los modos de uso, siendo la cerámica decorada relacio- 
nada con actos rituales y la cerámica lisa relegada a los fogones de los hogares. Las formas globulares, hemisféricas y de botellas, junto a ollas y pequeños cuencos hemisféricos y globulares de base cóncava, todos nos informan que los alimentos se prepararon a modo de caldos y gachas.

Respecto a la cerámica decorada, si bien la vajilla del interior peninsular se caracteriza por tener uno o varios motivos decorativos, buena parte de los elementos de sujeción han sido considerados adornos (mamelones, perforaciones y asas -tipo orejeta, cinta y asas puente). Las técnicas decorativas empleadas son acanaladura o incisión-acanaladura e impresión-acanaladura (Fig. 7), la técnica de boquique antiguo y el engobe rojo o 'a la almagra'. En cuanto a la decoración acanalada, inciso-acanalada e impreso-acanalada cuando los motivos son verticales se distribuyen en el borde de la cerámica y cuando son horizontales lo hacen en la panza. También se encuentran motivos de espiga, cordones paralelos a la boca con o sin incisiones $\mathrm{o} / \mathrm{y}$ digitaciones, mamelones poco salientes, decoración a peine $\mathrm{y}$ triángulos con impresiones -estas dos últimas posiblemente sea de horizontes calcolíticos-. Además, encontramos la cerámica aguada o 'a la almagra' y las escasas cerámicas con incisiones rellenas de pasta blanca ${ }^{15}$.

Hoy por hoy el estudio tipológico de la cerámica sigue dominando la investigación de la Meseta. Sin embargo, ha llegado el momento en el que se necesitan análisis químicos y petrológicos de las pastas cerámicas de las vajillas, tanto decoradas como lisas, que indiquen el lugar de origen de las arcillas, las técnicas empleadas para su elaboración y el uso a las que estaban destinadas. Los trabajos de este tipo pueden dar cuantiosa información acerca de los modos de vida (nivel técnico y productivo de los 'alfares', número de centros de producción, lugar de extracción de la materia prima, contacto intergrupal e intragrupal de las diferentes comunidades, e incluso nos pueden indicar la función a la que estaban dedicadas: cocina, almacenamiento, ritual...). Pese a que los estudios de técnica y análisis de pastas cerámicas están presentes en la Península Ibérica desde los años ochenta con los trabajos de $\mathrm{M}^{\mathrm{a}}$.S. Navarrete y J. Capel, en la Meseta son de carácter excepcio-

${ }^{15}$ La Nogaleda (Municio y Ruiz Gálvez-Priego, 1986), Los Vascos y la Cueva del Aire (Rubio de Miguel, 2000) y El Espino (Lucas Pellicer et alii, 2001).

${ }^{16}$ Contamos con el análisis de la cerámica neolítica 'a la almagra' -aguada roja- de la Cueva de La Vaquera, en el estudio se demuestra que hubo doble cochura de las pastas para la nal ${ }^{16}$. Es evidente que uno de los trabajos ineludibles de la investigación dedicada al Neolítico del Interior es el estudio y análisis químico y petrológico de las cerámicas.

En los asentamientos también se documenta la industria lítica y ósea, cuyo papel es igualmente importante en la interpretación de aquellas comunidades neolíticas que habitaron el interior peninsular. Respecto a la lítica encontramos un mal endémico en la investigación: el escaso interés en las publicaciones por reflejar estudios porcentuales de la industria lítica, hecho que hace casi imposible la interpretación de los datos. Sin embargo, no hay que dejarse llevar por el desánimo.

La piedra pulimentada queda representada por molederas, manos de molinos, azuelas y hachas; en torno a la lítica tallada es visible una mayor tendencia hacia la industria sobre lasca que sobre lámina -La Deseada, Verdelpino, El Altotero, La Cañadilla de la Torre de Peñafiel ${ }^{17}$ y Teso del Oro-, a excepción de asentamientos con predominio de lámina -El Aire, La Vaquera, Los Barruecos de Malpartida y La Cañadilla (Cáceres)-. Los restos de útiles hallados son elementos de hoz, raederas, perforadores, buriles y raspadores, en cambio con escasa frecuencia se encuentran puntas de flechas y microlitos. Todos estos materiales denotan una actividad de producción de alimentos: la siega de cereal -elementos de hoz-, transformación del medio para poder acceder a áreas de labor o preparación de pastos -hachas y azuelas-, la conversión del grano en harinas -molederas y manos de molino-, el curtido de pieles para la confección de prendas de vestir -raederas, perforadores y buriles-, elaboración de artefactos de madera y hueso -raspadores, perforadores y buriles-.

Respecto a las puntas de flechas podrían indicar tanto las actividades cinegéticas como guerreras, ya que para ambos casos se utilizan las mismas armas. La guerra puede ser originada por diferentes motivos: tierras de caza, mujeres o posición dentro de la jerarquía del grupo; siendo más lejana la causa belli por razones de propiedad y excedente, debido a que existe solapamiento y continuidad en la ocupación del territorio, no hay dificultad en el acceso a los campamentos y tampoco se ocultaron los silos. Tal vez, una de las consecuencias bélicas que se haya de observar es la movilización de bienes y enseres,

fijación del engobe, esta técnica recuerda, según los autores, a la empleada en la cerámica 'a la almagra' de Carigüela, Granada (Estremera Portela y Villa González, 1999).

17 Yacimiento vallisoletano, poblado con tres niveles de ocupación, neolítico, celtibérico y romano (Martín Montes y Pérez Rodríguez Aragón, 1997). 
puesto que los vencedores se hacen con las posesiones de los vencidos. De este modo, en el momento de interpretar la dispersión de ciertos artículos, habría que sumar al 'intercambio' intergrupal la variable de adquisición de bienes mediante la lucha.

Los objetos de adorno encontrados en los asentamientos se reducen a fragmentos de brazaletes $-\mathrm{La}$ Cañadilla en Cáceres (González Cordero, 1999), Vega de los Morales en Toledo (Vallespín et alii, 1985), en Madrid La Flamenca, Las Esperillas- Soto del Hinojar, Depósito de Velilla (Muñoz LópezAstilleros, 1998) y La Deseada (Díaz del Río Español, 1999)-, cuentas de collar en fase II de La Vaquera (Estremera Portela, 1999) y hachas votivas en La Pinilla y La Cueva en Guadalajara (Jiménez Sanz et alii, 1997). Por otro lado, de la industria ósea nos han quedado vestigios de agujas, punzones y espátulas en La Vaquera y en Velilla de Osorno, e incluso anillos y una matriz preparada para obtenerlos en la fase I de La Vaquera.

Todos estos fragmentos de historia nos están ilustrando actividades cotidianas como el vestir, el adorno, la comida y la elaboración de útiles. No obstante, queda por dilucidar el papel que tuvo el trabajo de la madera y de la cestería, que a pesar de no haber quedado restos tangibles, al menos sí testimonios indirectos. De la madera contamos con los raspadores, azuelas, punzones y cuchillos de sierra necesarios para su preparado y transformación. A semejanza del trabajo del hueso, el uso de la madera fue muy superior al que en un primer momento se puede suponer, ya que si analizamos los hábitos de vida de las comunidades meseteñas advertimos que el acceso a la materia prima era mayor que en tiempos anteriores: respecto a la madera, en primer lugar, la expansión del bosque mediterráneo durante el holoceno y el uso de la piedra pulimentada favorecía la adquisición de este material. En segundo lugar, si admitimos que los grupos neolíticos practicaban el pastoreo y la agricultura de rozas, fue muy posible una mayor tala de árboles para obtener tierras de labor y pastos, con la consecuencia de aumentar la cantidad de madera destinada a cabañas, cerramientos y herramientas.

Por otro lado, es de esperar que la presencia de animales domésticos con huesos largos y cornamenta, junto con la continuidad del consumo de ciervo proporcionara mayor cantidad de materia prima. De esta manera parece dudoso que la industria maderera y ósea estuviera en declive, la causa de su ausen- cia en el registro arqueológico posiblemente se deba a la fragilidad de estos materiales ante suelos ácidos y la acción de los animales, especialmente los roedores.

Finalmente, pese a que tampoco se han hallado restos de cestería en la Meseta, contamos con paralelos de cestillos del VI y V milenio a.C. en la cueva de Los Murciélagos de Albuñol, Granada (Cacho Quesada et alii, 1996), cuyas decoraciones recuerdan a los motivos cerámicos. También, aunque sin presencia de decoración se descubrió la base de un cesto en la cueva Lóbrega, La Rioja (Barrio Gil y Ceniceros Herreros, 1991) y esterillas utilizadas para cubrir el suelo en de La Draga (Bosch Lloret et alii, 2000).

Respecto a la presencia de materiales exóticos en contextos funerarios y en asentamientos encontramos: conchas en Villamayor de Calatrava (Rojas Rodríguez-Malo y Villa González; 1995), en La Vaquera (Estremera Portela, 1999) o en La Ventana (Jiménez Guijarro y Sánchez Marco, 2002), fragmentos de brazaletes de mármol y pizarra en el sur de Madrid -La Flamenca II, La Esperilla- Soto del Hinojar, Cerro del Depósito de Velilla ${ }^{18}$ y La Deseada $^{19}$, en Toledo -Vega de los Morales $^{20}$ y en Cáceres -Cañadilla ${ }^{21}$. O modelos cerámicos afines a otras áreas de la península. Todos estos hallazgos son vestigios directos de reciprocidad y contacto con otras comunidades.

Igualmente, la localización de los asentamientos junto a vías naturales y zonas de paso de una región a otra nos indica de forma indirecta el mismo hecho. Todos estos datos nos están proponiendo que ideas y artefactos no necesariamente se movieron mediante la migración de poblaciones, sino a través de contactos intergrupales.

En resumen, parece que la conducta económica pudo estar basada en el aprovechamiento de una gran variedad de recursos tanto endógenos como exógenos, que en última instancia se debería a la continuidad de la estrategia de movilidad de los cazadores-recolectores.

\section{SIEMBRA Y COSECHA DE IDEAS}

Durante las tres cuartas partes del siglo $\mathrm{XX}$ hemos sido testigo de cómo, bajo los principios heredados del siglo XIX (evolucionismo, progreso cultural y degeneracionismo) la Meseta ha sido considerada marginal, dependiente y de carácter retar-

\footnotetext{
18 Muñoz López-Astillero, K.I. (1998).

19 Díaz del Río Español, P. (1999).
}

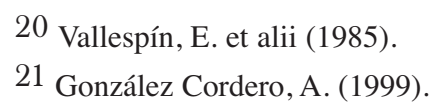


datario, y cómo, también, favoreció a la ecuación: pastores-cueva-nomadismo y agricultores-pobladosedentarización.

En los años veinte, Bosch Gimpera realizó el primer intento por sistematizar el interior identificando la Cultura Central, aunque ciertos hechos propiciaron que el Neolítico meseteño quedara oscurecido: (1) en primer lugar, la visión unilineal de la Historia hacía ver a aquellos pastores habitantes de cuevas como una fase necesaria para el posterior desarrollo de las civilizaciones prerromanas, quedando así la fase neolítica relegada a una etapa de transición, casi anecdótica. (2) Por otro lado, el hecho de que la investigación española no delimitara firmemente las fronteras entre el período neolítico y la etapa metalúrgica, unido a que hubo confusión y profusión terminológica, propició que numerosos 'fondos de cabaña' fueran olvidados. (3) En tercer lugar, y no desligado del punto anterior, la Cultura de las Cuevas o Central quedó reducido a un 'cajo de sastre', debido a la poca seriedad de investigadores y eruditos locales. (4) Finalmente, la consolidación del desierto meseteño fue debido a la radicalización de los anteriores hechos y llevar al extremo la idea de una Meseta habitada por reducidos y desperdigados grupos humanos.

Los primeros atisbos que señalaban la superación de este modelo clásico coincidieron con una serie de hechos: el descubrimiento de tres yacimientos fundamentales (Verdelpino, La Vaquera y El Aire), el comienzo de la política de autonomías y el relevo generacional en la investigación. Los tres descubrimientos cuestionaron el desierto meseteño, pero especialmente fue el abrigo de Verdelpino el que permitió un giro significativo en la interpretación del Neolítico meseteño: aportó un estrato epigravetiense con cerámica y dataciones absolutas que equiparaba el Neolítico Interior con otras zonas peninsulares, y además proporcionó niveles neolíticos con porcentaje de fauna salvaje consumida superior a la doméstica; lo que una vez más planteaba el viejo problema de la importancia del substrato epipaleolítico en la neolitización.

Tal fue el efecto que en la década de los ochenta se dio comienzo a una nueva denominación del Neolítico meseteño: el Neolítico Interior. Pese a que mantenía el carácter retardatario, dependiente del meridional y marginal, incluso los asentamientos seguían distinguiéndose en cueva y en alto, con el consecuente tipo de economía, ganadera y agrícola respectivamente; al menos esta reciente nomenclatura otorgó a la Meseta personalidad propia. Posteriormente, hacia la segunda mitad de la década de los ochenta se publicaron los primeros estudios recopilatorios sobre poblamiento, por Antona del Val, y el primer estado de la cuestión por Municio.

En los noventa se demostró que los asentamientos de superficie superaban a los de cueva y se distinguió un nuevo tipo de hábitat a media ladera, cuyas ventajas orográficas y climáticas pueden indicar también otras estrategias en la adquisición de recursos. Asimismo, se localizan asentamientos bajo túmulo que comparten características con el hábitat a media ladera; por otro lado, los asentamientos en alto de monte son denominados neolíticos con serias dudas. Como es visible, la Meseta deja de caracterizase por estar despoblada y por primar la vivienda en cueva, y, además, se cuestionan los poblados en alto.

También se suma otros dos hechos: (1) el solapamiento territorial entre las estaciones tanto neolíticas como entre las epipaleolíticas y neolíticas, de lo que se puede desprender varias hipótesis: la coetaneidad y continuidad de las diferentes comunidades, o alertarnos de una posible estrategia de supervivencia basada en la movilidad, de tal modo que Jiménez Guijarro ha propuesto el modelo habitacional estacional recurrente. (2) El segundo lugar, la continuidad entre el poblamiento epipaleolítico y neolítico se observa de forma directa en el abrigo de Verdelpino o en la covacha de La Higuera, de forma indirecta en los valles de Atapuerca y Sorbe.

En relación con el modo de vida llevado a cabo por las comunidades del interior peninsular hace 8000 años es muy difícil realizar afirmaciones. En principio durante el lapso de tiempo en el que el Neolítico nace, se desarrolla y desaparece transcurren 3000 años, durante los cuales converge gran diversidad de grupos humanos que tienden a comportarse de forma diferente. Un segundo aspecto es la heterogeneidad tanto ambiental como geográfica en la Meseta, situación que exige estrategias de subsistencia diferentes. En tercer lugar, en el centro peninsular hubo una gran diversidad de comunidades con peculiaridades culturales propias, que influyeron al comportamiento humano quedando impreso en el registro arqueológico.

Pese a que contamos con datos desprendidos de los asentamientos que permiten aventurar varias hipótesis, la escasez de análisis polínicos, faunísticos y tafonómicos dificultan la investigación sobre la economía y las diferentes estrategias desarrolladas por las primeras sociedades productoras de la Meseta. Los estudios paleoclimáticos han podido averiguar que el clima de la Meseta hace 8000 años era estépico y de carácter benigno, siendo semejante al actual, y que la cubierta vegetal no sufrió la acción del hombre (talas, praderas artificiales y cultivos) lo suficientemente agresiva como para quedar registrada en los análisis polínicos hasta el tercer milenio $\mathrm{BC}$. 
En estos último años hemos sido testigos de la multiplicación de asentamientos neolíticos meseteños. Si bien es cierto que se han localizado hábitats en cueva, en estos momentos el asentamiento característico del interior sería al aire libre, a media ladera, de carácter inestable, junto a pasos naturales, fuentes y afluentes de grandes ríos, cuya ubicación les permite un fácil y rápido acceso a los campos de labor, pastos y bosques, además de tener control visual del territorio. En torno a la ocupación de cuevas, covachas y abrigos parece estar relacionada con la serranía y con el acceso directo a pastos y a bosques, y a semejanza de lo ocurrido en otras zonas peninsulares, las oquedades comienzan a ser interpretadas bajo la sospecha de protagonizar un uso secundario: refugio, establo, almacén y/o recinto sagrado.

La aparente homogeneidad tanto en la selección del lugar del hábitat como en la inestabilidad y el solapamiento territorial de los asentamientos, nos induce a pensar que los modos de vida, aún con grandes diferencias entre sí, se basaban en la movilidad. Por otro lado, existen ejemplos de reutilización tanto del espacio como del territorio de las comunidades mesolíticas, que en última instancia participaban de una economía fundamentada en la movilidad, este hecho nos puede indicar que posiblemente hubo la continuidad de ciertas costumbres.

Hemos visto también cómo desde el principio, el estudio del poblamiento de la Meseta estaba acompasada en torno a la disputa: ganadería-cueva-nomadismo versus agricultura-poblado-sedentario. En un primer tiempo la presencia de yacimientos en cuevas consolidó la tesis de un interior con vocación ganadera y de carácter itinerante. Posteriormente los últimos descubrimientos están demostrando que el hábitat más común es al aire libre y de carácter inestable, como resultado a la nueva situación se han propuesto otros modelos económicos: amplio espectro, pluractividad y aldeano biestacional, aunque todos dan un mayor peso a la ganadería.

Por el contrario la actividad agrícola queda relegada a un segundo plano, a pesar de que la agricultura de roza proporciona gran movilidad a las comunidades $y$, si es a pequeña escala, no es lo suficientemente agresiva con el medio como para quedar representada en los análisis polínicos. En la Meseta se han documentado evidencias de laboreo de cereal -Triticum monococcum, Triticum diccocum y Triticum aestivum/durum- y leguminosas -Vicia y Lens-, también se han hallado estructuras de almacenamiento -silos y hoyos-, además de grandes contenedores cerámicos que igualmente pudieron servir para la conservación del grano. Estos descubrimientos nos están hablando de una economía de almace- namiento, o de 'stockage', y de una planificación de la actividad agraria.

Otra cuestión es la ausencia de ocultación de los silos, puesto que puede estar indicando que las relaciones intergrupales e intragrupales no eran lo suficientemente tensas (robo, saqueo o pago de tributos) como para provocar el escondite del grano. Según los datos extraídos de los asentamientos no hay diferencia entre las cabañas ni división del espacio doméstico, todo parece indicar que estaríamos ante familias nucleares cuya organización igualitaria se asemeja a las sociedades de bandas. Por el contrario, la presencia de enterramientos nos obliga a preguntarnos ¿por qué hubo individuos con el privilegio o agravio de ser enterrados?

Respecto a la ganadería, esta actividad queda representada por los escasos restos de fauna doméstica hallados. La cañada de ovicápridos se documenta desde época temprana, siendo además la más abundante, seguidamente hubo una diversificación con el consumo de bóvido y en menor medida de cerdo. Por otra parte, la ausencia de estudios arqueofaunisticos que desvelen la edad y el sexo de los animales sacrificados no nos permite asegurar la presencia de una economía eminentemente pastoril, no contamos con datos que especifiquen tal planificación y en qué medida estas comunidades dependieron de la ganadería. Sin embargo, la presencia de cerámica con formas globulares, de botella o de cuenco, ha sugerido que el preparado de alimentos se basaba en caldos, gachas y/o consumo de leche.

En cambio, la fauna salvaje consumida mantiene su presencia e incluso paridad con la fauna doméstica, aunque la caza parece convertirse poco a poco en una actividad de apoyo, siendo los animales más consumidos: ciervos, équidos y lagomorfos. Estas partidas de caza quedaron ilustradas en el Arte Esquemático, donde el ciervo es el animal más abatido.

En torno a la reciprocidad de bienes, existen evidencias directas de este hecho a través de los materiales exógenos que han aparecido en los yacimientos, como son las conchas marinas de Villamayor de Calatrava o de La Vaquera, o los brazaletes de mármol en la campiña madrileña y toledana. De forma indirecta la localización de los asentamientos en lugares cercanos a vías de comunicación y la aparente estrategia económica basada en la movilidad de estos pueblos, les permitiría el contacto intergrupal y un posible 'intercambio' de en seres, favores y trabajo.

Finalmente, hemos sido testigos de cómo la visión tradicional de la Meseta se ha ido transfigurando en un espacio heterogéneo, aunque con ciertos tintes de uniformidad: asentamientos a media altura y una economía basada en la movilidad y 
aprovechamiento de una amplia gama de recursos. Igualmente en estas características se observa cierta continuidad con el substrato epipaleolítico, ya que comparten tanto el gusto por los mismos espacios y como por fundamentar su modo de vida en la movilidad.

\section{Bibliografía}

ALDAY RUIZ, A. (1997): "Yacimiento de Atxoste (Vírgala la Mayor, Arraia-Maeztu". Arkeoikuska 97, 75-83.

ANTONA DEL VAL, V. (1986): “Aproximación a la problemática del neolítico en la meseta: una propuesta de secuencia cultural". Wad-Al- Hayara, 13.

ARNÁIZ ALONSO, M.A y ESPARZA ARROYO, A. (1985): "El yacimiento al aire libre del neolítico del Interior: El Altotero de Modubar (Burgos)". B.S.A.A., LI, 5-45.

ATIENZA BALLANO, M. (1995): Evolución del paisaje vegetal en la Sierras de Béjar y Francia durante el Holoceno, a partir del análisis polínico. Tesis Doctoral, Universidad de Alcalá de Henares.

BADAL GARCÍA, E. (2002): "Bosques, campos y pastos: el potencial económico de la vegetación mediterránea”. Saguntum, Extra 5, 129-145.

BARRIO MARTÍN, J. y RUBIO De MIGUEL, I. (2002): "El yacimiento Neolítico del Covacho de la Higuera". Estudios de Prehistoria y Arqueología Madrileñas, 12, 23-56.

BORDAS TISSIER, A. et alii (1996): "El asentamiento al aire libre del neolítico antiguo en la Font de Ros (Berga, Barcelona)". I ${ }^{\circ}$ Congrés del Neolític a la Península Ibérica, Rubricatum, 1, 397-406.

BOSCH GIMPERA, P. (1974): "El poblamiento antiguo y la formación de los pueblos de España". Paletnología, 1-468, Graz- Austria.

BOSCH LLORET, J. et alii (2000): El poblat lacustre neolític de La Draga, excavacions de 1990-1998. Girona.

BUENO RAMÍREZ, P. et alii (2002): “Áreas habitacionales y funerarias en el neolítico de la cuenca interior del Tajo: La provincia de Toledo". Trabajo de Prehistoria, 59, 65-79.

BUENO RAMÍREZ, P. et alii (2005 a): “Alimentación y economía en contextos habitacionales y funerarios del Neolítico meseteño". III Congreso del Neolítico en la Península Ibérica, 83-102. Santander.

BUENO RAMÍREZ, P. et alii (2005 b): El domen de Azután (Toledo). Áreas de habitación y áreas fune- rarias en la cuenca interior del Tajo. UAH Monografías 02. Alcalá de Henares.

BUXO, R. (1999): Arqueología de las plantas. Barcelona.

CASSIRER, E. (2000): Antropología filosófica. México.

CERRILLO CUENCA, E. et alii (2002): "La secuencia cultural de las primeras sociedades productoras en Extremadura: una datación absoluta del yacimiento de Los Barruecos (Malpartida de Cáceres, Cáceres)". Trabajos de Prehistoria, 59 (2), 101-111.

CERRILLO CUENCA, E. y GONZÁLEZ CORDERO, A. (2006): "El Neolítico Antiguo en la cuenca media del Tajo: estado actual de los conocimientos". $I V^{o}$ Congresso de arqueologia peninsular, Ed. Universidade do Algarve, 3, 183-196. Algarve.

CACHO QUESADA, C. et alii (1996): "La cestería decorada de la cueva de los Murciélagos (Albuñol, Granada)". Complutum Extra, 6 (I), 105-122.

CRIADO BOADO, F. et alii (2000): "Los túmulos como asentamientos". III ${ }^{\circ}$ Congresso de Arqueología Peninsular, A.D.E.C.A.P., 3, 289-302.

CHILDE, V.G. (1971): Teoría de la Historia. Buenos Aires.

CHILDE, V.G. (1997): Los orígenes de la civilización. México.

CHILDE, V.G. (2002): Qué sucedió en la Historia. Barcelona.

DARWIN, C. (2002): El Origen del Hombre (y la selección en relación al sexo). Buenos Aires.

DELIBES De CASTRO, G y Zapatero Magadaleno, P. (1995): "De lugar de habitación a sepulcro monumental: una reflexión sobre la trayectoria del yacimiento neolítico de la Velilla, en Osorno (Palencia)". I I Congrés del Neolític a la Península Ibérica, Rubricatum, 1, 337-348.

DENELL, R. (1999): Prehistoria económica de Europa. Barcelona.

DÍAZ Del RÍO ESPAÑOL, P. (1998): El III y II milenio a.C. en el entorno de la campiña madrileña. Tesis Doctoral, Universidad Autónoma de Madrid.

DÍAZ Del RÍO, P. y CONSUEGRA, S. (1999): "Primeras evidencia de estructuras de habitación y almacenaje neolíticas en el entorno de la campiña madrileña: el yacimiento de La Deseada (Rivas-Vaciamadrid, Madrid)". II $^{\circ}$ Congrés del Neolític a la Península Ibérica, Saguntum, Extra-2, 251-257.

ESTREMERA PORTELA, M". S. (1999): "Sobre la trayectoria del neolítico interior: precisiones a la secuencia de la cueva de La Vaquera (Torreiglesias, 
Segovia)". II ${ }^{\circ}$ Congrés del Neolític a la Península Ibérica, Saguntum, Extra-2, 245-250.

ESTREMERA PORTELA, M ${ }^{\mathrm{a}}$.S. (2003): Los primeros agricultores y ganaderos de la meseta norte: el Neolítico de la cueva de La Vaquera (Torreiglesias, Segovia). Serie Arqueológica en Castilla y León, Memorias: 11, Zamora

ESTREMERA PORTELA, Mª . S. y VILLA GONZÁLEZ (1999): "Las Almagras neolíticas de la Cueva de La Vaquera (Segovia). Las transformaciones de la goethita en relación con los cambios de color de la pintura cerámica”. B.S.A.A., LXX, 43-52.

FERNÁNDEZ- MIRANDA, M. y MOURE ROMANILLO, A. (1975): "Abrigo de Verdelpino (Cuenca). Nuevo yacimiento neolítico en el interior de la Península Ibérica". N.A.H., 3, 191-242.

FERNÁNDEZ-POSSE y de ARNÁIZ, M. D. (1980): "Los materiales de la cueva del Aire de Patones (Madrid)". N.A.H., 10, 39-64.

GONZÁLEZ CORDERO, A. (1999): "Comunidades neolíticas en los riberos alto extremeños del Tajo". II ${ }^{\circ}$ Congrés del Neolític a la Península Ibérica, Saguntum, Extra-2, 531-540.

GUILAINE, J. et alii (1995): Les excavacions a la Balma de la Margineda (1979-1991). Andorra.

GUTIÉRREZ PALACIOS, A. (1961): "El poblado de la Peña Bardal (Diego Álvaro, Ávila)". VII Congreso Nacional de Arqueología, 162-167.

HERNANDO, A. (1999): Los primeros agricultores de la Península Ibérica. Madrid.

HERNANDO, A. (2000): Arqueología de la identidad. Madrid.

IGLESIAS MARTÍNEZ, J. et alii (1995): "Estado de la cuestión sobre el neolítico en la submeseta norte". I ${ }^{\circ}$ Congrés del Neolític a la Península Ibérica, Rubricatum, 1, 721-733.

JIMÉNEZ GUIJARRO, J. (1998): "La neolitización en la cuenca alta del Tajo. Nuevas propuestas interpretativas para el Neolítico de la Meseta”. Complutum, 9, 27-47.

JIMÉNEZ GUIJARRO, J. (1999): "El proceso de neolitización del interior peninsular". II ${ }^{\circ}$ Congrés del Neolític a la Península Ibérica, Saguntum, Extra-2, 493-50.

JIMÉNEZ GUIJARRO, J. (2001 a): "Caracterización del epipaleolítico del interior peninsular". Estudios de Prehistoria y Arqueología madrileños, 10, 37-44.

JIMÉNEZ GUIJARRO, J. (2001 b): "El yacimiento de Valdivia (Madrid)". Estudios de Prehistoria y Arqueología madrileño, 10, 59-68.
JIMÉNEZ GUIJARRO, J. y SÁNCHEZ MARCO, A. (2004): “ La Cueva de La Ventana: datos arqueológicos y faunísticos para la interpretación paleoecológica del Neolítico Interior". Zona Arqueológica, 4 , vol 4, 253-263.

JIMÉNEZ SANZ et alii (1997): "Nuevos datos sobre el neolítico meseteño: la provincia de Guadalajara". $I I^{o}$ Congreso de Arqueología Peninsular, Tomo 2, Ed.Fundación Rei Afonso Henriques, 33-47.

JUAN-CABANILLES, J. y MARTÍ OLIVER, B. (2002): "Poblamiento y procesos culturales en la Península Ibérica del VII al V milenio A.C. (8.000-5500 BP). Una cartografía de la neolitización”. Saguntum, Extra-5, 45-77.

KUNST, M. y ROJO GUERRA, M. (1999): "El valle de Ambrona : un ejemplo de la primera colonización de las tierras del interior peninsular". II $^{\circ}$ Congrés del Neolític a la Península Ibérica, Saguntum, Extra-2, 254-270.

LÓPEZ SÁEZ, J.A. y LÓPEZ GARCÍA, P. (2005): "Análisis palinológicos en el dolmen de Azután (Toledo): una aproximación a los inicios de la agricultura y la ganadería en la meseta sur". El dolmen de Azután (Toledo): áreas de habitación y áreas funerarias en la cuenca interior del Tajo, 225-234. Madrid.

LUCAS PELLICER, M M.R., et alii (2001): "Cronología por TL del yacimiento neolítico de "El Espino" (Barranco del Duratón)". S.P.A.L, 10, 167-176.

LUBBOCK, J. (1876): L' homme préhistorique. París.

LUBBOCK, J. (1987): Los Orígenes de la Civilización y Sobre la condición primitiva del Hombre. Barcelona.

MALUQUER De MOTES, J. (1958): "Excavaciones arqueológicas en el Cerro del Berrueco". Acta Salamanticensia, Filosofía y Letras, Salamanca.

MALUQUER De MOTES, J. (1968): Humanidad Prehistórica, Barcelona.

MARTÍN MONTES, M.A. y PÉREZ RODRÍGUEZARAGÓN, F. (1997): "Un nuevo yacimiento neolítico al aire libre en la Meseta Norte. La Cañadilla de Torre de Peñafiel (Valladolid)". B.S.A.A., LXVIII, 31-48.

MARTÍ, A. et alii (2005): "Ca l’Oliaire (Berga, Barcelona), un asentamiento neolítico en el umbral del IV milenio con residuos de sal y de productos lácteos". III ${ }^{\circ}$ Congreso del Neolítico en la Península Ibérica. 175-186. Santander.

MERCADER FLORÍN, J. et alii (1989 a): "Materiales del neolítico del Valle del Jarama". Trabajos de Prehistoria, 46, 255-260. 
MERCADER FLORÍN, J. et alii (1989 b): "Nuevos materiales neolíticos y de la edad del bronce en el término municipal de Madrid". Estudios de Prehistoria y Arqueología Madrileñas, 21-82.

MUNICIO, L. (1988): "El neolítico en la meseta central española". Neolítico en España, 299-327, Madrid.

MUNICIO, L. y RUIZ-GÁLVEZ PRIEGO, M. (1986): "Un nuevo yacimiento neolítico en la meseta norte: las cerámicas decoradas de la cueva de la Nogaleda, Villaseca (Segovia)". Numantina, 143-157.

MUÑOZ LÓPEZ-ASTILLEROS, I. K. (1998): El poblamiento desde el Neolítico Final a la Primera Edad del Hierro en la cuenca Media del Tajo. Tesis Doctoral, Universidad Complutense de Madrid.

NAVARRO RUIZ, M. (2002): Asentamientos prehistóricos en la sierra de Atapuerca. Burgos.

NILSSON, S. (1868): Les habitants primitifs de la Scandinavie esaie d'ethographie comaparée. Primière Partie: l'age de la pierre. París.

OBERMAIER, H. (1917): Yacimiento prehistórico de las Carolinas (Madrid). Memoria de investigación paleontológica y prehistórica, 16, Madrid.

OBERMAIER, H. (1932): El hombre prehistórico y los orígenes de la humanidad. Madrid.

PALOMINO LÁZARO, A. y ROJO GUERRA, M. (1997): "Un nuevo yacimiento neolítico de habitación infratumular: "El Teso del Oro", en San Martín de Valderaduey (Zamora)". $I^{\circ}$ Congreso de Arqueología Peninsular, Tomo 2, Ed. Fundación Rei Afonso Henriques, 249-256.

PASTOR MUÑOZ, J. (2000): “Ocupaciones prehistóricas en el curso fluvial del río Sorbe. Provincia de Guadalajara. Comunidad de Castilla- La Mancha (II)". Wad-al-Hayara, 27.

PÉREZ DE BARRADAS, J. (1926): "El neolítico de la provincia de Madrid". R.B.A.M. del Ayuntamiento de Madrid, III, 75-87.

RAMOS ROMERO, M. et alii (1995): Las Batuecas y Las Hurdes. Salamanca.

RASILLA VIVES. M., et alii (1996): "El abrigo del Verdelpino (Cuenca). Revisión de su evolución sedimentaria y arqueológica". Complutum, Extra-6 (I), 75-82.

RODRÍGUEZ GONZÁLEZ, D. (2006): "Historia de la investigación y estado de la cuestión del Neolítico en Castilla-La Mancha: una visión de conjunto". $I V^{o}$ Congresso de arqueologia peninsular, Tomo 3, Ed. Universidade do Algarve, 217-228.

ROJAS RODRÍGUEZ-MALo, A.L. y VILLA GONZÁLEZ, J.R. (1995): "Una inhumación indivi- dual de época neolítica en Villamayor de Calatrava (Ciudad Real)". I ${ }^{\circ}$ Congrés del Neolìtic a la Península Ibérica, Gava-Bellaterra, Rubricatum, 1, 509-515.

ROJO GUERRA, M. A. y ESTREMERA PORTELA, Mª S. (2000): "El Valle de Ambrona y la cueva de La Vaquera: testimonios de la primera ocupación neolítica en la cuenca del Duero". III ${ }^{\circ}$ Congresso de Arqueologia Peninsular, Vol III, A.D.E.C.A.P.S., 8196.

ROJO GUERRA, M. y KUNST, M. (1999): “La Lámpara y Peña Abuela. Propuesta secuencial del Neolítico interior en el ámbito funerario". II $^{\circ}$ Congrés del Neolític a la Península Ibérica, Saguntum- Plav, Extra-2, 503-512.

ROJO GUERRA, M. et alii (2002): "El fuego como procedimiento de clausura en tres tumbas monumentales de la submeseta norte". Studia Archaelogica, 91, 21-38.

RUBIO DE MIGUEL, I. (1984/85): "En torno a la problemática del hábitat al aire libre en el Neolítico Peninsular". CuPAUAM, 11-12, 153-161.

RUBIO DE MIGUEL, I. (1988): "La economía de subsistencia en el Neolítico Hispano". Neolítico de España, 337-418, Madrid.

RUBIO DE MIGUEL, I. (1995): "Las periodizaciones del Neolítico Peninsular. Una perspectiva historiográfica". Verdolay, 7, 31-39.

RUBIO DE MIGUEL, I. (2000): "Las primeras sociedades agrícolas en Madrid. Neolítico y Calcolítico precampaniforme”. Boletín de la Asociación Española de Amigos de la Arqueología, 39/40, 105-126.

SAN VALERO, J. (1954): El Neolítico Hispánico. Madrid.

SÁNCHEZ MARCO, A. et alii. (2005): "Primeros datos faunísticos del Neolítico madrileño: la cueva de La Ventana (Torrelaguna, Madrid)". III ${ }^{\circ}$ Congreso del Neolítico en la Península Ibérica. 155-166. Santander.

SERVICE, E.R. (1984): Los cazadores. Barcelona

TRESSERRAS, J.J. y MATAMALA, J. (2005): “Estudio de restos microscópicos y compuestos orgánicos en utillaje de molido y contenido de vasijas". El dolmen de Azután (Toledo): áreas de habitación y áreas funerarias en la cuenca interior del Tajo, 234-241. Madrid.

TUBINO, F. M" (1872): "Historia y progreso de la Arqueología Prehistórica". Museo Español de Antigüedades, 29 (1), 9-24, Madrid 
TYLOR, E.B. (1977): Cultura Primitiva. Origen de la Cultura. Madrid.

VALLESPÍN, E. et alii (1985): Materiales del Neolítico Final-Eneolíticos de la Vega de los Morales (Aldea del Rey, Ciudad Real). Ciudad Real.

VIGIL-ESCALERA, A. y MORENO, A. (1996): "Materiales Arqueológicos de la calle de la Cal, números 15/17 ". Reunión de Arqueología Madrileña, 91-93.

VILLA GONZÁLEZ, J.R. y ROJAS RODRÍGUEZMALO, J.M. (1995): “Aportación al conocimiento del Neolítico en la cuenca media del Tajo". I ${ }^{\circ}$
Congrés del Neolìtic a la Península Ibérica, Rubricatum, 707-714.

ZAMORA, A. (1975): Excavación en la Cueva de la Vaquera, Torreiglesias (Segovia). Segovia.

ZAPATERO MAGADALENO, P. (1993): “Un posible nuevo sepulcro dolménico en la provincia de Palencia". B.S.A.A., LIX, 39-46.

ZAPATERO MAGADALENO, P. (1991): "Sobre las relaciones entre el Neolítico interior y Megalitismo". B.S.A.A., LVII, 53-65. 


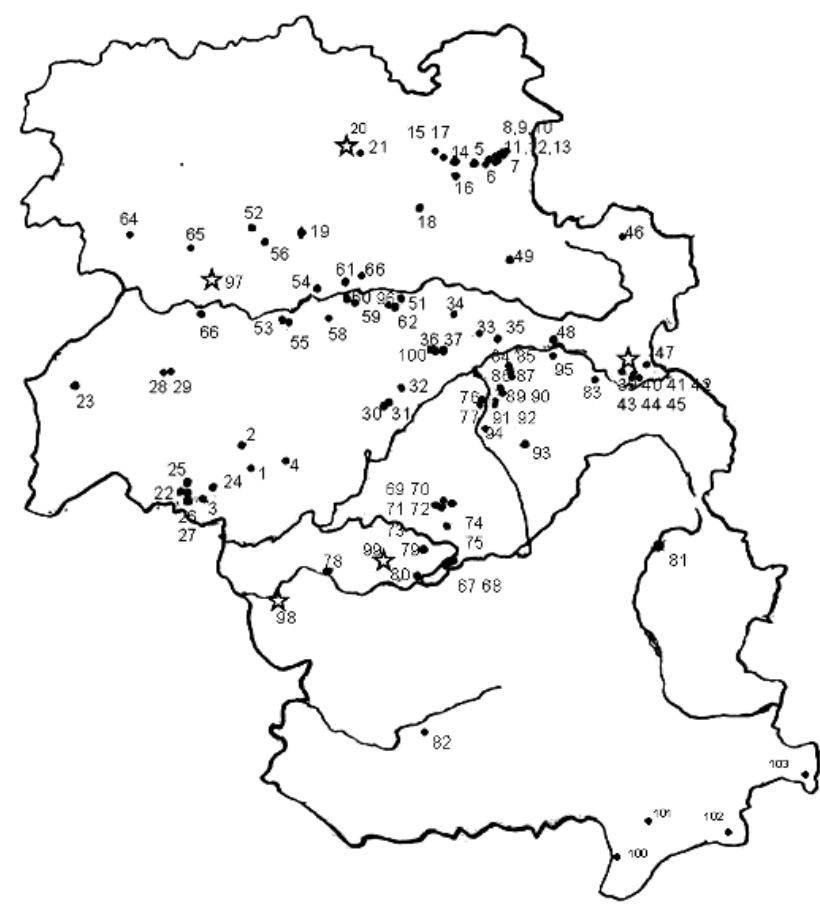

\author{
SORIA \\ 39- LOS VIVAREJOS (AMBRONA) \\ 40- LA REVILLA (AMBRONA) \\ 42- HAZA DEL CONEJO (AMBRONA) \\ 43- EL POZUELO (AMBRONA) \\ 43- \\ 45- LA CUMBRE (CONQUEZUELA) \\ 46- LA VIÑUELA (MONTUENGA) \\ 47- EL SABINAR (MONTUENGA) \\ 48- ABRIGOS VARIOS (TORREVICENTE) \\ 49- UCEROI (UCERON) \\ V ALL AD OLID \\ 50- EL CRISTO (BOLAÑOS DE CAMPOS) \\ 51- UNCABO (CASTILO DEL DUERO) \\ 52- LAS COTARRILLAS (ISCAR) \\ 53- LA ISLA I| (LA SECA) \\ 54- EL TENDERIN -LAS CUBAS (LAGUNA DEL DUERO) \\ 55- LAS CUEVASI (MATA POZUELO) \\ 56- LA CAÑADA (MORALES DEL CAMPO) \\ 57- LA CANNADA (PEDRAJAS DE SAN ESTEBAN) \\ 58- LLANO MESADO II (PORTLLO) \\ 59- LOS ARENALES (SANTIBAÑEZ DE VALCORBA) \\ 60- EL CARRASCAL (TRASPINEDO) \\ 61- VIÑAS DE ABAJO (VIШABAÑEZ) \\ 62- LA CAÑADILLA (TORREPEÑAFIEL) \\ 96- VALTEINA (TORREPEÑAFIEL) \\ 63- LA SINOVA II (MLLAVAQUERIN) \\ ZAMOR A \\ 64- EL CASTILO (CABAÑAS DE ALISTE) \\ 65- LA PERRONA (GEMA) \\ - FUEN TE DE SAN PEDRO MLLAFAFILA) \\ 97- TESO DEL ORO (S.MARTIN DE VALDERADUEY)
}

\title{
CASTILLA YLEÓN
}

ÁVIL A

MADRID

67- LA FLAMENCA II (ARANJUEZ)

68- LAS ESPERILLAS-SO TO DEL HINOJAR

(ARANJUEZ)

69- LOS VASCOS (VILLAVERDE)

70- VALDIVIA (VILAVERDE)

71- VERONA II VILLAVERDE BAJO)

2- LA PEÑA DEL BARDAL (DIEGO ÁLVARO)

3- LA TETA (GILBUENA)

4--LOS ITUEROS (STA. MARÍA DEL ARROYO)

71- VERONA (II (VILLAVERDE BAJO)

5- GALERIA DEL SÍLEX (ATAPUERCA)

5- GALERIA DEL SILEX (ATAPUER

6- LA BARRACA (ATAPUERCA)

7- CAMNNO DELCHORRON (VALLE DE ATAP)

作

73- S.MARTÍN DE LA VEGA KM.3,5 (S.MARTÍN DE LA VEGA)

74- LA DESEADA (RIBAS VACIAMADRID)

75- ARENERO DE ARGANDA (ARGANDA)

76- CUEVA DEL AIRE (PATONES)

9- CAMNNO REAL (VALLE DE ATAPUERCA)

11- PRADO GRANDE (VALLE DE ATAPUERCA)

12- EL MIUAR (VAШE DE ATAPUERCA)

13- CARDEÑAJIMENO II (VAШE DE ATAPUERCA)

14- VILLAFRÍA III (BURGOS)

15- CUEVA DE VALDEGOBA (HUERMECES)

16- EL ALTOTERO (MODUBAR DE LA EMPREDRADA)

16- EL ALTOTERO (MODUBAR DE LA EMPREDRADA)
17- LOS CASCAJOS-EL BLANQUIUO (QUINTADUENAS)

PALENCIA

18- CASERIO DE ESCUDEROS (STA.MARÍA DEL CAMPO)

77- CUEVA DE LA HIGUERA (PATONES)

\section{CASTILLA LA MANCHA}

TOLEDO

78- MESEGAR DEL TAJ O (PK.45,200 DE LA CM.4000)

79- LOS VALLADORES (YUNCOS)

80- DEPÓSITO DE LA VELILLA (MOCEJÓN)

98- DOLMEN DE AZUTÁN (AZUTÁN)

99- DOLMEN DE CASTILLEJOS (CASTILLEJOS)

CUENCA

81- VERDELPINO (CUENCA)

8IUDAD REAL

20- LA VEULLA (OSORNO)

21- SAN CEBRIÁN (BARCENA. DE CAMPOS)

$S$ AL AMANC A

GUAD AL AJAR A

83- LA PINILLA (ANQUITA)

84- SORBE II (VALLE DEL SORBE)

85- SORBE III (VALLF DEL SORBE)

86- SORBE VI (VALLE DEL SORBE)

87- SORBE VII NALLE DEL SORBE)

88- CUEVA DE LA HOZ (STA. MARÍA DEL ESPINO)

89- CUEVA DE PASO (TAMA.JÓN)

90- LOS ENEBRALES (TAMA.JÓN)

90- LOS ENEBRALES (TAMAJON)
91- CUEVA DEL RENO (VALDESOTO)

92- JARAMA II (VALDESOTO)

93- TALAYUELA (TÓR TOLA DE HENARES)

94- EL DESTE TE (VALDEPENNAS DE LA SIERRA)

95- LA CUEVA (BAÑUELOS)

\section{ALB ACETE}

100-MOLINO DEL VADICO (YESTE)

101-CUEVA DEL NIÑO (AYNA)

102-FUEN TE DE ISSO (HELLIN )

35- STB-1 (SAN TIBANEZ DE AYШON)

36- LA NOGALEDA (VILLASECA)

38- LA SOLANA DE LA ANGOSTURA (ENCINAS)

103- CUEVA SANTA (CAUDETE)

Fig 1.- Con la inauguración de los noventa los asentamientos neolíticos se multiplicaron, quedado en clara minoría el hábitat en cueva frente al de superficie, además frente a la clasificación clásica -en cueva y en alto- surgen nuevos modelos de asentamiento a media altura y bajo túmulo, aunque ambos patrones tan sólo se diferencian en el hecho de estar o no relacionados con un recinto funerario (túmulo o megalito). La siguiente ilustración recoge la distribución de los yacimientos neolíticos con función de hábitat en la Meseta Central: asentamientos neolíticos (en cueva y al aire libre) y ó asentamientos bajo túmulo. 


\begin{tabular}{|c|c|c|c|c|c|c|c|}
\hline Yacimiento & $\begin{array}{c}\text { Ref. } \\
\text { Laboratorio }\end{array}$ & Datación & Muestra & Nivel & \multicolumn{2}{|c|}{$\begin{array}{c}\text { Calibración } \\
\text { BC } \\
\end{array}$} & Bibliografía \\
\hline Verdelpino & $\begin{array}{l}\text { CSIC- 153B } \\
\text { CSIC-150B } \\
\text { CSIC-152B } \\
\text { CSIC-151B }\end{array}$ & $\begin{array}{l}7950^{+} /-150 \\
5170^{+} /-130 \\
5120^{+} /-130 \\
4630^{+} /-130\end{array}$ & & $\begin{array}{l}\text { N.IV.Corte2 } \\
\text { N.III.Corte } 1 \\
\text { N. III.Corte } 2 \\
\text { N. II.Corte } 2\end{array}$ & $\begin{array}{l}-7300 \\
-4350 \\
-4250 \\
-3700\end{array}$ & $\begin{array}{l}-6450 \\
-3700 \\
-3650 \\
-2900\end{array}$ & $\begin{array}{l}\text { Fernández Miranda } \\
\text { y Moure Romanillo } \\
(1975)\end{array}$ \\
\hline $\begin{array}{l}\text { Arenero de } \\
\text { los Vascos }\end{array}$ & $\begin{array}{l}\text { Laboratorio de } \\
\text { Datación y } \\
\text { Radioquímica de } \\
\text { la UAM (T.L) }\end{array}$ & $6430^{+} /-450$ & Cerámica & & & & $\begin{array}{l}\text { Rubio de Miguel } \\
(2001)\end{array}$ \\
\hline $\begin{array}{l}\text { Arenero de } \\
\text { Valdivia } \\
\text { Oeste y } \\
\text { Centro }\end{array}$ & $\begin{array}{l}\text { Laboratorio de } \\
\text { Datación y } \\
\text { Radioquímica de } \\
\text { la UAM (T.L) }\end{array}$ & $\begin{array}{l}6327^{+} /-480 \\
5741^{+} /-470\end{array}$ & Cerámica & & & & $\begin{array}{l}\text { Rubio de Miguel } \\
(2001)\end{array}$ \\
\hline La Lámpara & $\begin{array}{l}\text { KIA-8874 } \\
\text { KIA-4780 } \\
\text { KIA-6790 }\end{array}$ & $\begin{array}{l}6421^{+} /-30 \\
6390^{+} /-60 \\
6055^{+} /-34\end{array}$ & $\begin{array}{l}\text { Hueso } \\
\text { humano }\end{array}$ & $\begin{array}{l}\text { Fosa enterra- } \\
\text { miento }\end{array}$ & $\begin{array}{l}-5480 \\
-5480 \\
-5050\end{array}$ & $\begin{array}{l}-5320 \\
-5220 \\
-4840\end{array}$ & $\begin{array}{l}\text { Rojo Guerra y } \\
\text { Kunst (1999-a) }\end{array}$ \\
\hline La Velilla & $\begin{array}{l}\text { Gr.N-20327 } \\
\\
\text { Gr.N-17166 } \\
\text { Gr.N-17167 } \\
\text { Gr.N-18487 }\end{array}$ & $\begin{array}{c}6130+/-190 \\
\\
5250^{+} /-50 \\
5200^{+} /-55 \\
5195^{+} /-155\end{array}$ & & $\begin{array}{l}\text { Horizonte de } \\
\quad \text { cabaña } \\
\text { Horizonte de } \\
\text { hogares }\end{array}$ & $\begin{array}{l}-5500 \\
-4240 \\
-4230 \\
-4350\end{array}$ & $\begin{array}{l}-4600 \\
-3960 \\
-3810 \\
-3650\end{array}$ & $\begin{array}{l}\text { Delibes y Zapatero } \\
\text { (1995) }\end{array}$ \\
\hline La Vaquera & $\begin{array}{l}\text { Laboratorio } \\
\text { UAM (T.L) } \\
\text { GrN-22933 } \\
\text { GrA-9228 } \\
\text { GrN-17386 } \\
\text { GrN-18340 } \\
\text { GrA-8241 } \\
\text { GrN-22930 } \\
\text { GrN-22929 } \\
\text { GrN-23561 } \\
\text { GrN-23560 } \\
\text { GrN-23564 } \\
\text { GrN-23559 }\end{array}$ & $\begin{array}{c}6050+-140 \\
5920+-50 \\
6760+-80 \\
6780+-180 \\
6080+-70 \\
6170+-60 \\
5800+-30 \\
4670+-90 \\
4850+-80 \\
4880+-60 \\
4690+-120\end{array}$ & $\begin{array}{r}\text { Carbón } \\
\text { “6 } \\
\text { “6 } \\
\text { “6 } \\
\text { “6 } \\
\text { 6 } \\
\text { 6 } \\
\text { “6 } \\
\text { “ }\end{array}$ & $\begin{array}{c}\text { Fase I } \\
\text { Base de cueva } \\
\\
\text { N.105 } \\
\text { N.104 } \\
\text { N.103 } \\
\text { N.103 } \\
\text { N.98 } \\
\text { N.92 } \\
\text { Fase II } \\
\text { N.90 } \\
\text { N.85 } \\
\text { N.80 } \\
\text { Fase III } \\
\text { Hoyo } 14 \\
\text { N.62 }\end{array}$ & $\begin{array}{l}3032^{+} /- \\
-5350 \\
-4940 \\
-5810 \\
-6050 \\
-5220 \\
-5300 \\
-4720 \\
-3650 \\
-3800 \\
-3800 \\
-3750\end{array}$ & $\begin{array}{l}336 \\
-4600 \\
-4690 \\
-5520 \\
-5350 \\
-4830 \\
-4960 \\
-4550 \\
-3100 \\
-3350 \\
-3520 \\
-3050\end{array}$ & $\begin{array}{l}\text { Rubio y Blasco } \\
(1988-1989) \\
\text { Estremera Portela } \\
(2003)\end{array}$ \\
\hline El Espino & $\begin{array}{l}\text { MAD-1048 (TL) } \\
\text { MAD-1049 (TL) } \\
\text { MAD-1050 (TL) } \\
\text { MAD-1051 (TL) } \\
\text { MAD-1052 (TL) }\end{array}$ & $\begin{array}{l}6409+-563 \\
6486+-577 \\
6089+-529 \\
6128+-598 \\
6323+-738 \\
\end{array}$ & $\begin{array}{l}\text { C.Mamelón } \\
\text { C. Lisa } \\
\text { C. Incisa } \\
\text { C.Colorante } \\
\text { C. Impresa } \\
\end{array}$ & $\begin{array}{c}\text { Superficie } \\
\text { ، } \\
\text { 6 } \\
\text { " } \\
\text { 6 } \\
\end{array}$ & & & $\begin{array}{l}\text { Lucas Pellicer et } \\
\text { alii (2001) }\end{array}$ \\
\hline La Ventana & Beta-166231 & $6350+-40$ & Hueso & $\begin{array}{l}\text { Hogar B } \\
\text { Nivel III }\end{array}$ & -5470 & -5220 & \\
\hline $\begin{array}{l}\text { Los } \\
\text { Barruecos }\end{array}$ & $\begin{array}{l}\text { Beta-159899 } \\
\text { Beta-171124 }\end{array}$ & $\begin{array}{l}6060+-50 \\
6080+-40\end{array}$ & $\begin{array}{l}\text { Carbones } \\
\text { Carbones }\end{array}$ & $\begin{array}{l}\text { Silo } 1 \\
\text { Hogar }\end{array}$ & $\begin{array}{l}-5210 \\
-5210\end{array}$ & $\begin{array}{l}-4800 \\
-4840\end{array}$ & $\begin{array}{l}\text { Cerrillo et alii } \\
(2002)\end{array}$ \\
\hline
\end{tabular}

Fig 2.- Tabla de dataciones absolutas recogidas en los yacimientos meseteños. Calibración con OxCal v3.10 Bronk Ramsey (2005). 


\begin{tabular}{|c|c|c|c|}
\hline $\begin{array}{l}\text { Fase de vegetación } \\
\text { (tipos característicos) }\end{array}$ & $\begin{array}{c}\text { Asignación } \\
\text { cronológica y climática }\end{array}$ & Impacto antrópico & Indicadores \\
\hline Olea y Quercus ilex-t & & $\begin{array}{c}2^{\circ} \text { periodo agrícola } \\
\text { olea, cereales, castanea }\end{array}$ & Curva continua de Olea \\
\hline $\begin{array}{c}\text { Castanea y Quercus } \\
\text { robur- } t\end{array}$ & $\begin{array}{l}\text { SUBATLANTICO } \\
\text { Cálido y húmedo }\end{array}$ & $\begin{array}{c}1^{\circ} \text { periodo agrícola } \\
\text { castanea, junglans, vitis }\end{array}$ & $\begin{array}{l}\text { Curva continua de } \\
\text { Castanea }\end{array}$ \\
\hline Pinus & $\begin{array}{l}\text { SUB-BOREAL } \\
\text { Templado y seco. } \\
\text { Enfriamiento } \\
(5000-2500 \mathrm{BP})\end{array}$ & $\begin{array}{c}\text { Periodo ganadero } \\
\text { Ericaceae, platago. } \\
\text { Fuerte deforestación } \\
\text { Dipsacaceae, } \\
\text { plumbagineceae }\end{array}$ & Base máxima de Pinus \\
\hline Betula y Carpinus & $\begin{array}{c}\text { ATLANTICO } \\
\text { Templado y húmedo. } \\
\text { Con } 2^{\circ} \mathrm{C} \text { por encima de } \\
\text { la media actual. } \\
(8000-5000 \mathrm{BP})\end{array}$ & & $\begin{array}{c}\text { Base de la curva } \\
\text { continua de Alanus } \\
\text { Base máxima de Betula }\end{array}$ \\
\hline $\begin{array}{l}\text { Quercetum Mixtum, } \\
\text { Betula y Pinus }\end{array}$ & $\begin{array}{l}\text { BOREAL } \\
\text { Frío y húmedo } \\
(9000-8000 \mathrm{BP})\end{array}$ & & $\begin{array}{c}\text { Codominancia Betula y } \\
\text { Pinus }\end{array}$ \\
\hline Pinus y Quercus & $\begin{array}{l}\text { PREBOREAL } \\
\text { Seco y frío }\end{array}$ & & \\
\hline
\end{tabular}

Fig 3.- Durante el Sub-Boreal el impacto antrópico no es visible hasta el tercer milenio, momento en el que se expanden las praderas y pastos artificiales y se detectan los primeros cultivos de cereales. En diferentes yacimientos meseteños se han documentado restos de cereal tipo Triticum monococcum -presente desde el IV milenio en la Península Ibérica-, diccocum y aestivum/ durum compactum -conocido desde el Neolítico Antiguo- y de leguminosas Vicia y Lens, testimonios que junto con los silos, hoyos y grandes recipientes cerámicos están indicando una actividad agrícola con una pla-

nificación previa. En la ilustración vemos la evolución paleoambiental de la Meseta desde el Preboreal hasta el Subatlántico.

[Fuente: cuadro basado en materiales de Atienza Ballano (1995), Jiménez Guijarro (1998)

y Barrio Martín y Rubio de Miguel (2002)].

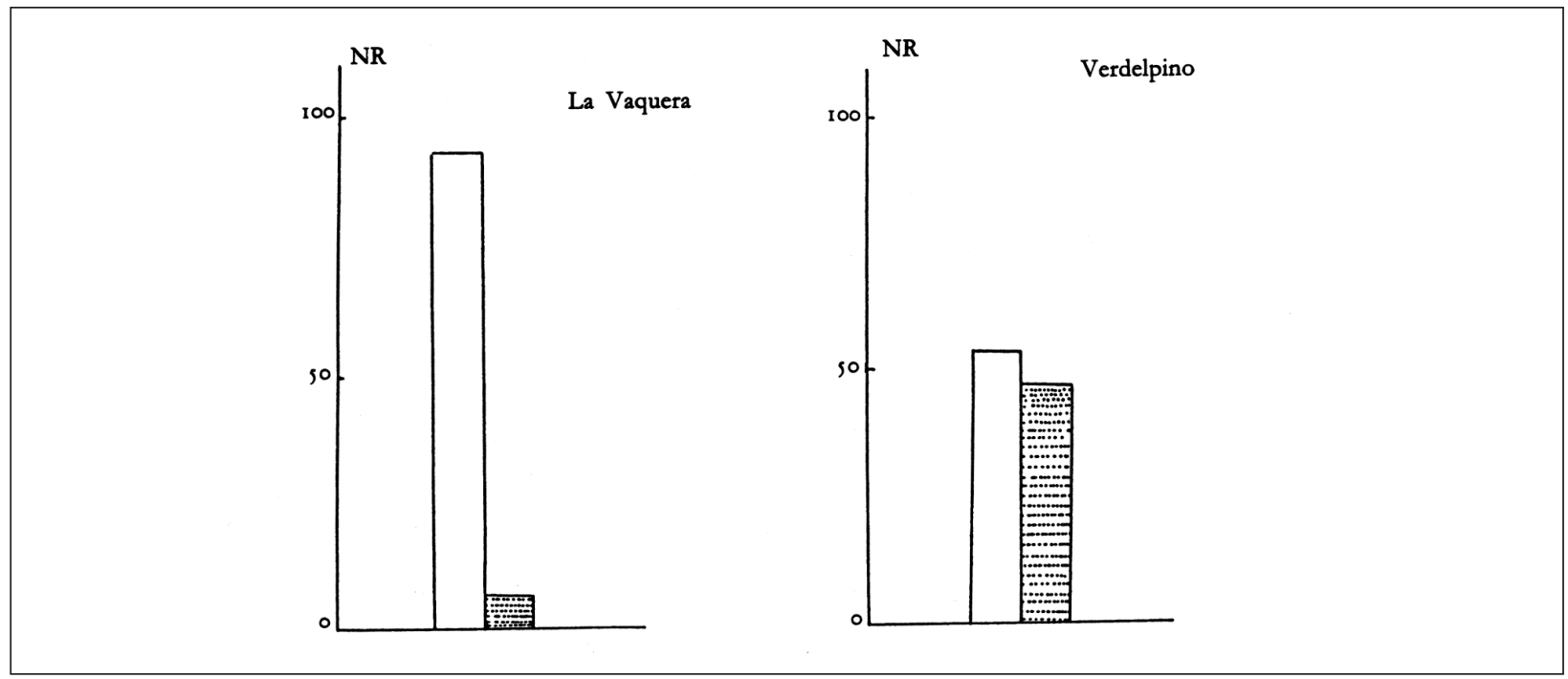

Fig 4.- Durante el Neolítico los niveles de fauna doméstica y salvaje mantienen la paridad, tan sólo al final del Neolítico la caza comienza a ser una actividad de apoyo. Dentro de los animales domésticos los ovicápridos tienen una presencia temprana en el Meseta para posteriormente rivalizar con los bóvidos y en menor medida con el cerdo. En este histograma se representan los porcentajes de la fauna doméstica y salvaje de los niveles neolíticos en los yacimientos del Abrigo de Verdelpino y La Vaquera.

[Fuente: Rubio de Miguel (1988:394)]. 


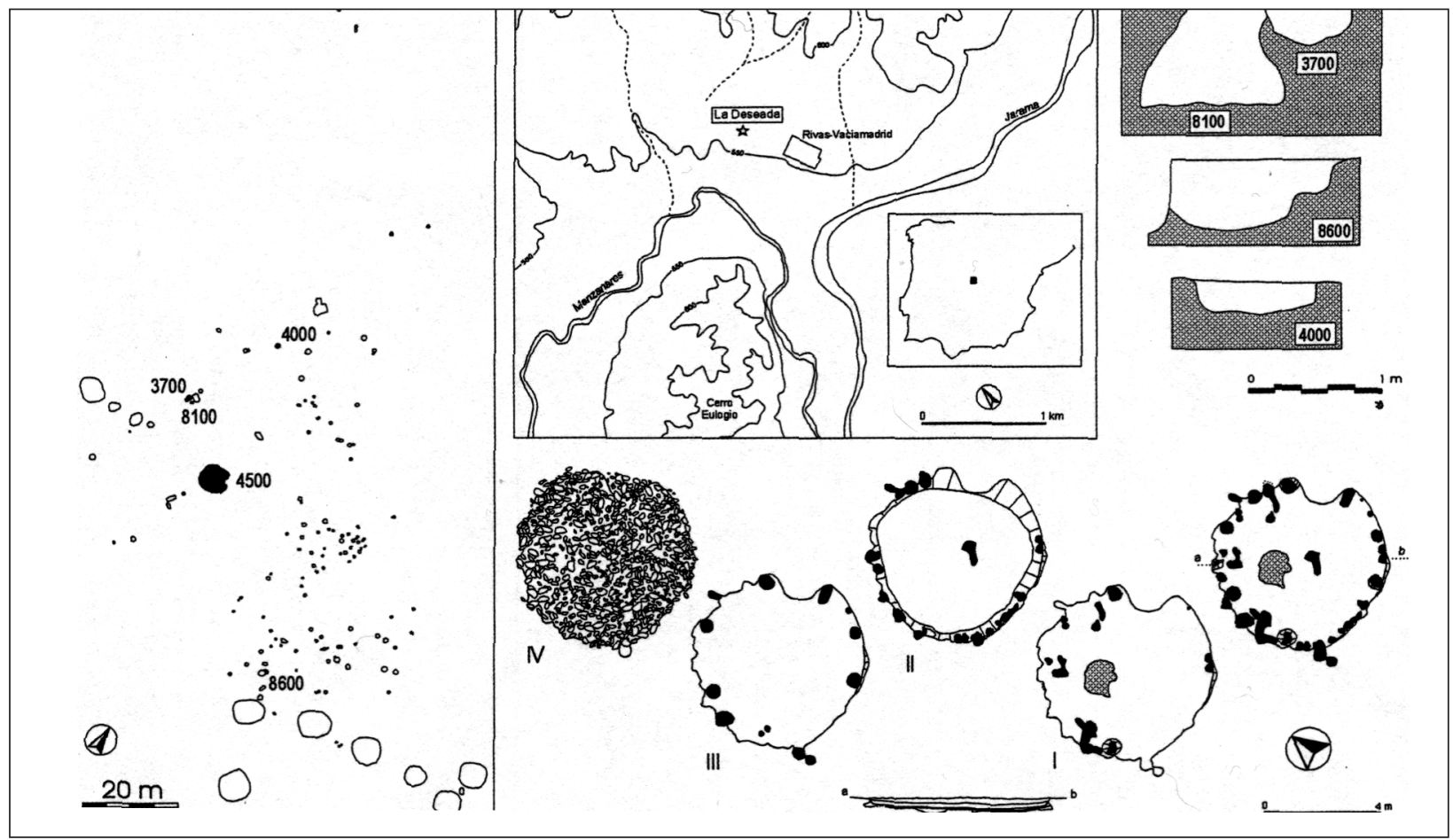

Fig 5.- Las cabañas conservan un hogar central y los silos se encuentran sin ocultamiento, pudiendo ser interpretado como la ausencia de tensiones intragrupales e intergrupales entre la comunidades neolíticas. La ilustración recoge la ubicación y la distribución de la cabaña y del yacimiento de La Deseada (Rivas-Vaciamadrid, Madrid). [Fuente: Díaz del Río-Español y Consuegra (1999: 252)].

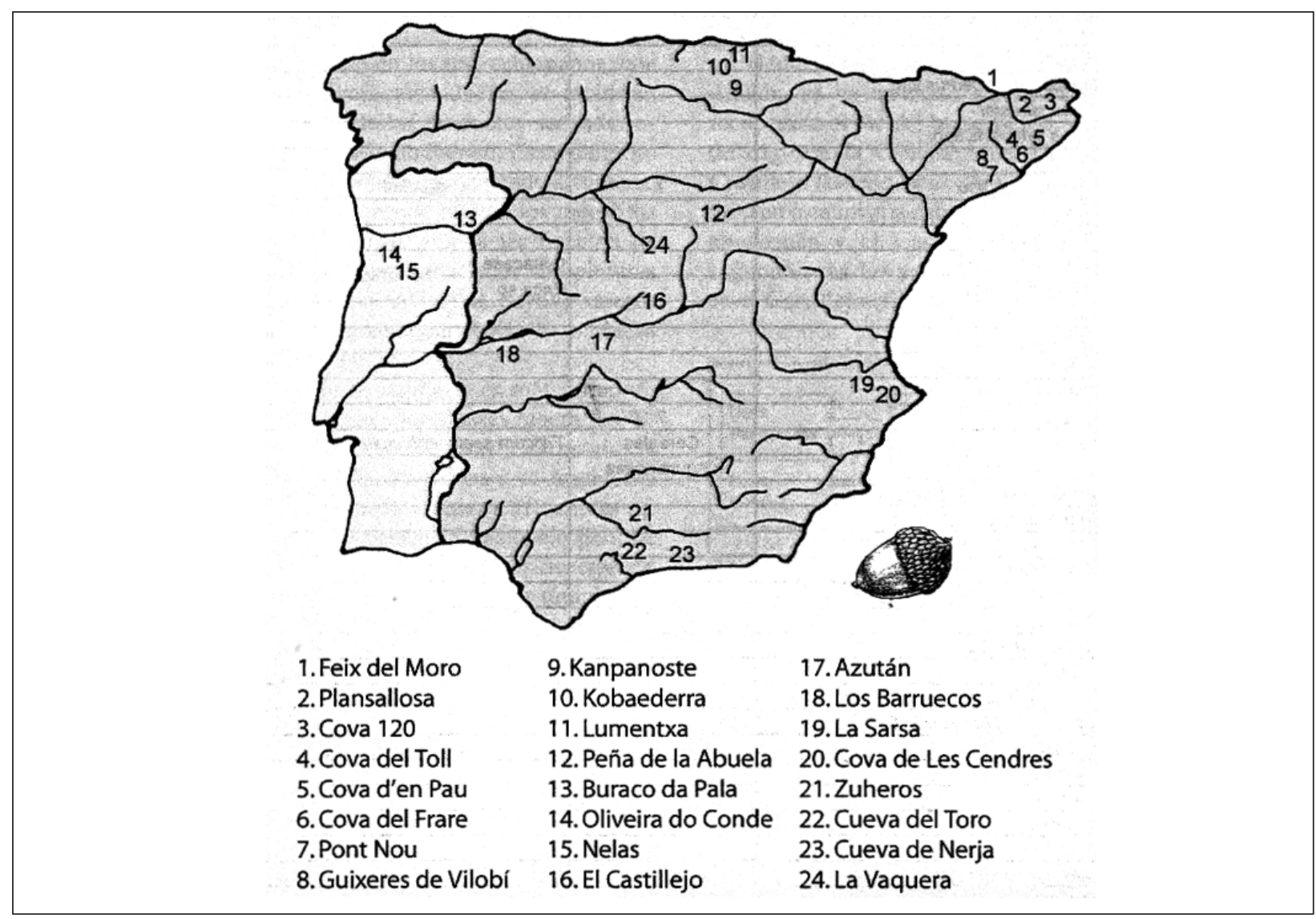

Fig 6.- Yacimientos neolíticos peninsulares con datos sobre el consumo humano de la bellota con prácticas de la agricultura del trigo. [Fuente: Bueno Ramírez et alii, 2005: 88) 


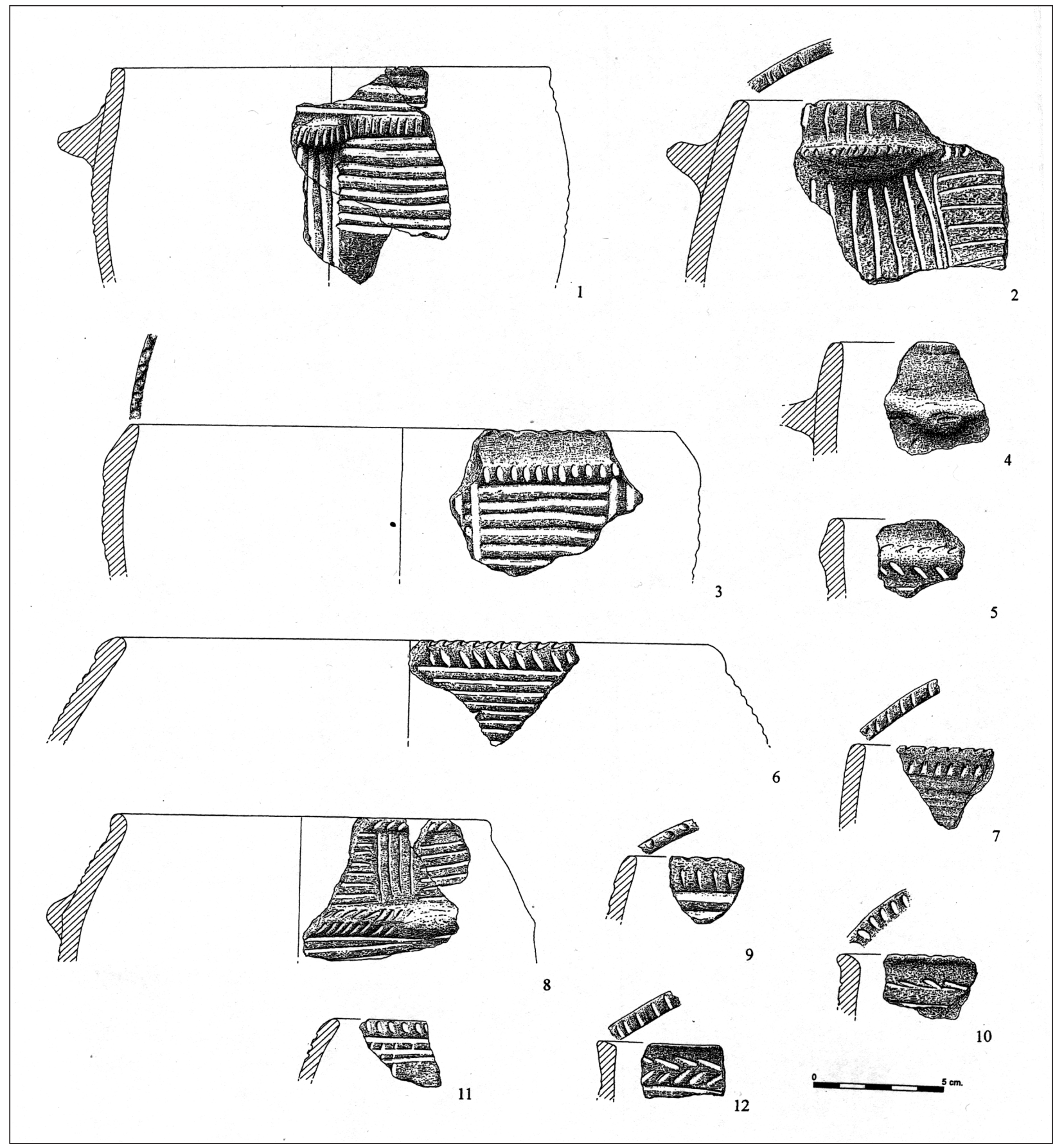

Fig 7.- Muestra del material cerámico decorado de la Cueva de La Vaquera. La pieza 1), 2) y 8) son ejemplos de cerámica globular y de gran tamaño con asas, con mamelones aplanados los dos primeros y con asas de orejeta horizontales el último. También presentan el característico cordón paralelo a la boca de la vasija con incisiones o dentados, aunque es más evidente en la figura 3). Los cordones con motivo 'en espiga' (5, 10 y 12). Por otro lado, la técnica decorativa impreso-acanalada está presente en todas las cerámicas y los motivos son geométricos con líneas paralelas e incluso con triángulos invertidos. Finalmente, queda por mencionar las impresiones de los labios elemento muy común en la cerámica de La Vaquera.

[Fuente: Estremera Portela, 2003: 114]. 